\title{
LA INTERVENCIÓN MUSICAL EN LAS EXEQUIAS REALES DE LA CATEDRAL DE CUENCA (1598-1621) ${ }^{1}$
}

\author{
POR \\ José Luis de la Fuente Charfolé \\ Doctor en Filosofía y Letras, \\ Profesor Titular de Música de la Universidad de Castilla-La Mancha
}

\begin{abstract}
RESUMEN
El artículo discute la unicidad musical en el oficio de difuntos a partir de un primer acercamiento a los actos exequiales que tuvieron lugar en la catedral de Cuenca entre 1598 y 1621, relacionados con los óbitos de Felipe II, Margarita de Austria y Felipe III: ceremonias de acusada magnificencia, reiteradas en las principales capitales españolas. Tras el análisis de su organización el artículo incluye la transcripción de cinco documentos asociados que contienen datos inéditos de interés histórico y artístico.
\end{abstract}

Palabras Clave: Historia de la Música, Musicología, Música, Catedral, Capilla musical, Instituciones religiosas, Fiesta religiosa, Felipe II, Margarita de Austria, Felipe III, Cuenca

\section{THE MUSIC INTERVENTION IN ROYAL FUNERALS IN THE CATHEDRAL OF CUENCA (1598-1621)}

\begin{abstract}
The article discusses the uniqueness of music in the office of the dead from a first look at Funeral acts that took place in the cathedral of Cuenca between
\end{abstract}

\footnotetext{
${ }^{1}$ Fuentes documentales consultadas para la elaboración del artículo. AC: Actas Capitulares $(E-C U c$. Sección Secretaría $/ \mathrm{n}^{\circ}$ de libro: folio) / LC: Libros de Cuentas $\left(E-C U c\right.$. Sección Cuentas $/ \mathrm{n}^{\circ}$ de libro: folio) / L: Legajos (CUm. Negociado de personal) / P: Protocolos (CUh. Signatura) / I: Inventarios (E-CUC. Signatura). ABREviaTuRAs. Las referencias a los archivos consultados respetan la terminología RISM Library Sigla. E-Mn. Madrid: Biblioteca Nacional. / E-Mpa. Madrid: Archivo General del Palacio Real. / E-Mh. Madrid: Archivo Histórico Nacional. / E-CUc. Cuenca: Archivo de la Catedral. / E-CUd.
} 
1598 and 1621, related to the deaths of Philip II, Margaret of Austria and Philip III: ceremonies of marked magnificence, repeated in major Spanish cities. After analyzing your organization the article includes the transcription of five documents that contain data associated unpublished historical and artistic interest.

KEY WORDS: History of music, Musicology, Music, Cathedral, Music chapel, Religious institutions, Sacred Festivity, Philip II, Margaret of Austria, Philip III, Cuenca

Recibido/Received 01-03-2012

Aceptado/Accepted 18-04-2012

Esperat Iustus in morte sua.

(Proverbios, 24)

\section{INTRODUCCIÓN}

Nadie puede negar que nos hallamos en una época donde la ciencia y la tecnología dominan la realidad. Esa misma ciencia, que ha conseguido trabar conocimiento del espacio exterior y desplazar partículas infinitesimales a la velocidad de la luz, ignora qué tipo de conexiones permiten a dos átomos, inicialmente unidos, interaccionar entre sí aún cuando permanecen separados miles de kilómetros. Esa misma ciencia ha desistido del estudio de lo inmaterial e intangible, y por tanto de los únicos mecanismos trascendentales al ser humano - no conozco otros que lo sean más - como el misterio de la vida, de la muerte, y del retorno, considerados todos ellos enigmas eternos, espirituales, absolutamente impenetrables.

En la sociedad actual, oficialmente laica, la muerte no tiene el significado divino que tuvo en la época de los Austrias, cuando el devotismo ocupaba el centro místico de todas las vidas: pocas cosas, salvo los noticiarios y los hospitales nos la recuerdan hoy con la efectividad que tuvo antaño. La muerte ha dejado de estar representada en nuestros recorridos habituales, y cuando aparece lo hace soslayando la consciencia; la escasez iconográfica incide directamente en su olvido: La traducción de la fe en imágenes enriquece la relación con la creación y con la realidad sobrenatural, remontándose a las narraciones

Cuenca: Archivo Diocesano. / CUh. Cuenca: Archivo Histórico Provincial. / CUm. Cuenca: Archivo Municipal. / CC. Catálogo musical del Archivo de la Santa Iglesia Catedral Basílica de Cuenca (ver detalle en Bibliografía).

Hispania Sacra, LXV

131, enero-junio 2013, 103-138, ISSN: 0018-215-X, doi: 10.3989/hs.2013.004 
bíblicas y representando las diversas expresiones de la devoción popular. ${ }^{2}$ Cualquier signo que pudiera facilitarnos una mayor relación con este misterio, como anteriormente sucedía en lo simbólico con la figura de la vanitas y todas sus alegorías visuales y sonoras, sólo interesa al entorno artístico o crítico. Hoy día la muerte, como interés colectivo y parte consustancial de la vida, sólo se muestra cuando lleva asociado el drama morboso de la noticia la cual, a pesar de su ejemplaridad, resulta un espectáculo de escaso contenido crítico.

Unos siglos atrás, los ciudadanos del inestable Seiscientos vivieron la plenitud moralizante que impuso el absolutismo austriaco: una forma para sobrellevar aquel presente incierto que las epidemias y peligros cotidianos presagiaban corto. En este clima de oficialismo católico, el interés eclesial no difería del monárquico, manteniendo entre ambos una mínima y armónica separación denominada en diferentes líneas historiografías «tolerancia». La Iglesia se manifestó promoviendo acciones de evidencias palpables, con correspondencias en lo musical y en lo literario, como lo revelan los textos de la Pasión, o la Vita Christi - algo similar sucedió también en el ámbito profano con la novela picaresca -, pasajes en origen pensados para su exhibición pública con el propósito de aumentar la devoción popular.

En la España Moderna, la celebración de la muerte regia, iniciada como expresión cultural $-\mathrm{y}$ también artística-, ha mantenido parte de su interés entre estudiosos e historiadores, manifestándose en los variados puntos de vista que nutren la abundante historiografía existente, fundamentalmente centrada en el análisis de los túmulos. A pesar de su importancia, el estudio del hecho musical y su incidencia social como manifestación asociada al concepto de fiesta ${ }^{3}$ - propio de un momento donde las incipientes pautas barrocas apuntaban hacia valores sensistas - ha permanecido desvirtuado y mantenido en segundo plano. Según Javier Campos, el ceremonial de las exequias era común en España e Hispanoamérica. Desde luego, la afirmación de Campos no se cumple en lo musical, si se atiende a la diferencia entre el uso obituario del canto llano (en el caso peruano) frente a la creciente costumbre polifónica iniciada en España:

Fiesta barroca es fiesta de los sentidos porque ellos son los cauces por donde el mensaje intelectual (razón y fe), y la floración de afectos (gusto y placer), llegará al destinatario:

\footnotetext{
${ }^{2}$ Comisión pontificia para los bienes culturales de la iglesia. Carta circular: Necesidad y urgencia del inventario y catalogación de los bienes culturales de la iglesia, 10 de abril de 1994, Prot. n. 179/91/35. Véase también, carta circular La función pastoral de los archivos eclesiásticos, 2 de febrero de 1997, Prot. n. 274/92/118.

${ }^{3}$ La nota dice así: [...] si grandioso fue el Recibimiento que la ciudad le otorgara en vida en su única visita no le quiso ir a la zaga a la hora postrera de la despedida. Apud., Cuesta Hernández, L. J. 2008. «Mexico insigne honras celebro a su rey: algunas precisiones sobre el ceremonial fúnebre de la dinastía de los Austrias en la Nueva España», en Via Spiritus, 15, pp. 111-136, en p. 113.
} 
[...] Veamos unos ejemplos: VISTA: «más era una vistosa representación la que por junto ofrecía a los ojos...» Oído: «Comenzó el coro las vísperas del Oficio de difuntos... en canto llano, que a todos los bien entendidos pareció una superior y admirable representación...» TAсто: «Existen infinidad de alusiones a tipos y variedad de tejidos, tan familiarizados con este órgano de los sentidos: bayeta de Castila, paño fino de Segovia, anascote, raso, brocado, terciopelo bordado en oro... ${ }^{4}$

\section{Previos civiles}

Siempre que tenía lugar un fallecimiento real, éste era comunicado desde la Corte tanto a los poderes civiles como al estamento eclesiástico del reino. Normalmente el Corregidor recibía un oficio confirmando el deceso, con datos sobre las circunstancias y hora de la muerte, ordenando la realización de los actos necesarios para conseguir el máximo esplendor, dignidad y grandeza en una ceremonia que se debía realizar ante una gran cantidad de gentes de toda la comarca que, con seguridad, acudiría a celebrar la efeméride: [...] vbo infinita gente de la çiudad, que no se podia andar por la Yglesia y todos los corredores de la nabe, de una parte y de otra, ocupados de mucha gente. ${ }^{5}$

El Corregidor daba cuenta del oficio al resto de autoridades - procurador, comendador, alguaciles y justicias -, la carta era públicamente leída ad verbum, tomando después los acuerdos y encargos necesarios para los lutos, honras y sufragios protocolarios. El Ayuntamiento devolvía una carta de pésame a la Corte, entregada directamente por un Regidor de la plaza, y se pregonaban por toda la ciudad, a golpe de bocina, las condiciones y días para los lutos. Era costumbre atenerse a lo hecho en anteriores ocasiones y, si procedía, se ordenaba su repetición modificando lo necesario para ajustar los actos a la nueva situación. En su momento se determinaba una comisión encargada de: a) la convocatoria de los inquisidores y oficiales del Santo oficio, y de todas las órdenes religiosas de la ciudad, a las exequias; ${ }^{6}$ b) conseguir cera en abundancia y repartir los lutos entre las autoridades de obligada asistencia, a rraçon de ocho baras de bayeta de a doce rreales $;{ }^{7}$ c) ordenar el pregón de la subasta

\footnotetext{
${ }^{4}$ Campos y Fernández de Sevilla, J. 2001. «Exequias en honor de Felipe III celebradas en Lima en 1621», en Hispania Sacra, 53, p. 344.

${ }^{5} A C, 109: 51 \mathrm{v}$.

${ }^{6}$ Las órdenes fueron: frailes de San Pablo de la orden de Santo Domingo, frailes de San Agustín, frailes de San Francisco, frailes descalzos de hábito franciscano, frailes de la Santísima Trinidad, frailes de Nuestra Señora de la Merced y clérigos de la Compañía de Jesús.

${ }^{7}$ El luto quedó decretado para todos los ciudadanos de Cuenca y sus tierras, mayores de siete años. Los documentos concretan con detalle las obligaciones ciudadanas que abarcaban desde el ropaje: traygan el bestido negro pudiendo y sonbrero sin toquilla y no cosa de seda so pena de seiscientos maravedis y perdido el vestido aplicado como dicho es y diez dias de carcel no tiniendo vestido negro solo
} 
pública para la traza del túmulo; d) encontrar un predicador con elocuencia y habilidad probadas, capaz de conmover las conciencias; e) finalmente, los comisionados se reunían con el deán, dignidades y canónigos de la Catedral, para fijar las fechas en que se iban a celebrar las exequias y el lugar catedralicio en que se iba a colocar el armazón tumular.

El primer oficio religioso tenía lugar la víspera de la misa de difuntos por la tarde. Las autoridades y las principales órdenes religiosas iniciaban un breve y fastuoso recorrido procesional, camino del túmulo. La comitiva se iniciaba tras el toque de campanas de la catedral, seguido del tañido de las demás iglesias y monasterios de la ciudad que daban dobles largos y clamores de mucha tristeza. La duración del acto convertía el oficio en una auténtica velada que duraba hasta altas horas de la madrugada. Según el protocolo civil la comitiva partía desde dentro de las casas del Ayuntamiento, donde los regidores, justicia y regimiento esperaban la llegada de los oficiales y fiscal de la inquisición, que junto al alcalde mayor y al médico se dirigían a caballo por su horden, con sus maceros delante, a la nave de los Reyes de la Catedral, lugar en que se había construido el túmulo funerario, donde ocupaban siempre en función de su rango las bancadas dispuestas junto al presbiterio. El ritual se repetía ampliado al día siguiente, a la hora de la misa mayor, y era celebrado simultáneamente en la nave central y en las capillas designadas para ello, con mucha solenidad, silencio y quietud.

\section{Vigilia religiosa}

La estructura del rito romano que celebraba la muerte cristiana mantuvo, en sus orígenes, una ordenación sencilla que fue lentamente regulada mediante decretos del papado. El arquetipo del denominado Oficio de difuntos quedó fijado a partir del Concilio de Trento como una disposición cerrada, compuesta por vísperas, maitines y laudes: liturgias mortuorias reguladas en el Ceremoniale Episcoporum que tenían lugar en las iglesias catedrales en las vísperas de Todos los Santos - siempre antes de completas - sin que en el resto de iglesias pudieran rezarse los maitines de difuntos hasta el día 2 de noviembre por la mañana.

traigan el sonbrero sin toquilla y las mugeres de las dichas personas tocados negros so la dicha pena; hasta la prohibición de manifestaciones musicales: Que ninguna persona de dia ni de noche públicamente por las calles ni a las puertas de sus casas ni de otra persona no puedan tocas viguela ni otro ynstrumento ni canten en manera alguna ni juegen a la pelota hasta que otra cosa se probea so pena de seiscientos maravedis y perdidos los ynstrumentos aplicados como dicho es y diez dias de carzel y ansi lo proveyo e mando [...]. CUm. Sig. 2740. Leg. 826. Exp. 13, s. f. Apud., Barrio Moya, J. L. 1983. «Las honras fúnebres de la Reina Margarita de Austria en la Catedral de Cuenca», en Cuenca, $n^{\circ} 21-22$, p. 59. 
Sin embargo, prevaleció la costumbre de rezar este oficio después de las vísperas de Todos los Santos, y así se sigue practicando hoy. ${ }^{8}$

Para ello, observándose las rúbricas, una vez dicho el Benedicamus Domino de vísperas y omitido el Fidelium animae, se comienza el oficio fúnebre; y del mismo modo se comienzan los maitines y laudes de difuntos después de los laudes del día (Rub. Gen. Brev., tit. xxx, $\mathrm{n}^{\circ}$ 3). Según el padre Gomar, las primeras vísperas deben rezarse el día anterior a la misa, considerando que, en caso de que se tenga que rezar un único nocturno, se debe tomar el que corresponda a la feria, según el Breviario establecido por Pío V en 1570; pero in die depositionis corpore presente se ha de rezar el primer nocturno con el invitatorio que se dice en la Conmemoración de los difuntos, en el día dipositionis, y siempre que se rezan los tres nocturnos.

Concreta Gomar que las oraciones que acompañen a los salmos deben decirse no sólo en vísperas, también en laudes, bien concluya con ellas el oficio o sigan a los maitines. Los versos que en vísperas y laudes se ponen al fin después del Pater noster, o después de los salmos Lauda anima y De profundis se rezan en singular cuando el oficio es por un solo difunto. ${ }^{9}$ El verso Requiem aeternam después de los salmos, en los responsorios y después de la oración al fin del oficio, así como en el verso Erue Domine antes de la primera lección, y el Requiescat in pace después de la oración: lo demás se reza según aparece en el Breviario (Rit. Rom. de Officio defunctorum). El orden establecido quedó perfectamente definido en De vesperis, et matutinis pro defunctis:

Via in officiis Defunctorum diversae ab aliis caeremoniae in multis observatur, ideo de eis est subiungendum: [...] Et nunc, si Episcopus ipsemet erit in crastinum celebraturus Missam solemnen pro defunctis, debebit etiam et in his Vesperis, et Matutinis officium facere: [...] et detecto capite, versus altare dicit secreto [Pater noster] usque in finem, et chorus incipit Antiphonam [Placebo Domino \&c] illam integre recitando ; qua finita et incepto Psalmo [Dilexi \&c] Epsicopus caput cooperit, et sedet ; et sic sedens manet, quosque inchoetur a choro [Magnificat \&c] Tunc furgit, et stat detecto capite usq ; in finem : et cum repetitur per chorum Antiphona post Magnificat, sedet ; [... Episcopus alte pronuntiat ea verba orationis Dominicae vedelicet [Et ne nos inducas \&c] cum aliis versiculis, respondente chor, quae habentur in Breviario post Vesperas defunctorum, et orationem [Fidelium Deus \&c] qua finita, versiculum [Requiem aeternam \&c] choro respondente [Et lux perpetua \&c] deinde chorus [Requiescat in pace]. Quo dicto, sedet Episcopus, cooperto capite, et post modicam moram surgit, capite detecto, dicit

\footnotetext{
${ }^{8}$ Ceremoniale Episcoporum iussu Clementis VIII, Pontificis Maximi novissime reformatum. Omnibus ecclesiis, praecipue autem Metropolitanis, Cathedralibus \& Collegiatis per utili, ac necessarium. Venetiis Ex Typographia Nicolai Misserini, Anno Iubilar MDC, Mense Septembris. Lib. 1, cap. XXVIII, p. 51-52.

${ }^{9}$ Los datos aportados han sido resumidos del trabajo de Gomar, J. 1885. «Difuntos», en Diccionario de Ciencias Eclesiásticas (N. A. Perujo y J. Pérez Angulo). Barcelona: Subirana Editores, p. 573.
}

Hispania Sacra, LXV

131, enero-junio 2013, 103-138, ISSN: 0018-215-X, doi: 10.3989/hs.2013.004 
secreto [Pater noster] quo dicto capite aperto chorus incipit Invitatorium [Regem, cui omnia vivunt] pro Matutinis cum psalmo [venite exultemus \&c] Cum chorus incipit psalmum primi nocturni $[\ldots]$ quosque dicatur per chorum responsorium versiculi ante primam lectionem primi nocturni [...] idem facit post responsorium versiculi tertii nocturni ante septimam lectionem. Lectiones ipsa cantatur per cantores, vel per canonicos, iuxta consuetudinem loci, in tono consueto lectionum, et Responsoria lectionum per chorum. Dicuntur deinde Psalmi cum suis Antiphonis pro Laudibus. ${ }^{10}$

\section{LAS EXEQUIAS Y SU DESARROLLO.}

\section{La organización hispánica: el caso de Cuenca}

Aunque la estructura musical del oficio de difuntos quedó estandarizada por los decretos tridentinos y las prohibiciones concretas en cuanto al uso de obras e instrumentos, la práctica española hizo suyas algunas modificaciones que fueron lenta e imperceptiblemente introducidas, según el juicio capitular del momento, único encargado de articular y distribuir el contenido competencial de cada interviniente en los diversos actos. Sabemos que no hubo participación instrumental en ninguno de los funerales reales pero no podemos asegurar que faltara el órgano, a pesar de la limitación expresa:

De organo, organista, et musicis seu cantoribus, et norma per eos servanda in divinis. In omnibus Dominicis, et ómnibus festis per annum accurrentibus, in quipus populi a servilibus operibus populi abstinere solent, decet in Ecclesia organum, et musicorum cantus adhiberi: $[\ldots]$ et quandocumque occurreret celebrare solemniter, et cum laetitit pro aliqua regravi. Quotiescumque Episcopus solemniter celebraturus Ecclesiam ingreditur, aut, re divina peracta, discedit, convenit pulsari organum. [...] In Missis et officiis defunctorum nec organo, nec musica, Quam figuratam vocant, utimur, sed cantu firmo, quem etiam in tempore Adventus et Quadragesimae in ferialibus diebus adhiberi convenit. ${ }^{11}$

Los intereses de la realeza por mantener este tipo de actos post mortem fueron múltiples, ante todo políticos, ya que con ellos se reflejaban en la sociedad los rasgos monárquicos más destacados: poder, grandeza, virtud y honestidad; todo ello amparado por una adhesión inquebrantable hacia la Iglesia Católica:

Dexó, pues, esta vida mortal el Gran Rey Felipe Tercero, y se hicieron solemnisimas Exequias en todo su Reyno a la Magestad Catolica, a la Grandeza Mayor de el Mundo, al Mayor Monarca de la Tierra, convertido en ella, a la Columna invencible de la Fe, el Espejo

\footnotetext{
${ }^{10}$ Ceremoniale Episcoporum, 1600: Lib. 2, cap. x, p. 81-82.

${ }^{11}$ Ceremoniale Episcoporum, 1600: Lib. 1, cap. XXVII, pp. 51-52.
} 
de la Honestidad, al Exemplo de la Juventud virtuosa, al Dechado de Santos, y Buenos Casados, a la Norma y Regla de la Viudez Santa, y Continente, al Rey mas Casto [...]. ${ }^{12}$

La regulación litúrgica destinada al efecto mantiene algunas diferencias cuando se comparan los mismos actos en diferentes lugares. El ceremonial se iniciaba con el toque de campana a prima: éste podía variar casi una hora dependiendo de la estación. Las vigilias funerarias comenzaban al atardecer (vísperas), siendo adelantadas en relación con su horario habitual (completas). La sección central (maitines) era la más flexible en el orden musical.

Entre los principales elementos de intervención musical se encuentran: en primer lugar, las antífonas, o melodías libres que establecen un diálogo fraseológico con los recitados y versos salmódicos, mantienendo con estos una relación «tonal» muy cercana; su formulación general es: $\left[A V_{1} A V_{2} A\right]$. Segundo, los responsorios, melodías complejas provenientes de la salmodia responsorial, con dos elementos: a) los versos, que alternan con: b) respuestas corales unisonales; en conjunto, se trata de una estuctura que se entrelaza con los versículos propios de cada nocturno. Sus variantes son múltiples, si bien aparece con frecuencia la forma de tres versículos, como ocurre en el Libera me Domine, $L U$ : 1767. Según Hoppin, este responsorio no corresponde a los maitines sino a la absolución posterior a la misa de difuntos, lugar en que se reitera el texto Requiem aeternam, en un tiempo y con un significado litúrgico totalmente diferente. ${ }^{13}$ No se considera adecuado el uso de la doxología en el oficio de difuntos; ésta es sustituida por el versículo Requiem aeternam dona eis Domine: et lux perpetua luceat eis.

Según el padre Samuel Rubio, la primera composición polifónica destinada al ceremonial obituario que se conserva es una misa pro defunctis, perteneciente al compositor del siglo Xv Johannes Ockeghem. ${ }^{14}$ Tal vez no fuera éste un precedente significativo para los músicos españoles que, a pesar de los fragmentos de Anchieta o Francisco de la Torre, no vieron proliferar piezas mortuorias hasta pasados los días de Pedro Escobar, incorporándose después a este uso los tradicionales nombres de Juan Vázquez (Agenda Defunctorum, 1556), Cristóbal de Morales o Tomás Luis de Victoria, compositores cuya genialidad les posibilitó acrisolar en sus obras la general severidad, propia de la funcionalidad de este tipo de piezas, con la particularidad de una esencia expresiva que hace del Oficio hispano un terreno definitorio - y definitivo - frente al usado en el resto de Europa.

${ }^{12}$ Yáñez, J. 1723. Memorias para la historia de don Felipe III, rey de España. Madrid: Nicolás Rodríguez Franco, Impressor de Libros, p. 270.

${ }^{13}$ Puede ampliarse este contenido en el texto de Hoppin, R. H. 1991. La música medieval. (Trad.: Pilar Ramos). Madrid: Akal Música, cap. IV, pp. 107-121.

${ }^{14}$ Rubio, S. 1983. Historia de la música española, 2. Madrid: Alianza Música, p. 80. 
La estructrura general queda articulada, primero, alrededor de una práctica iniciada en los primeros años del Seiscientos que incluyó la intervención polifónica en los tres nocturnos del oficio de maitines: no hemos encontrado referencias contradictorias que nos hagan pensar que esto era excepcional; segundo, que la polifonía interviene en las lectio y no en los responsorios, prueba evidente de que la práctica polifónica no estaba todavía consolidada. ${ }^{15}$ En el caso de la Catedral de Cuenca, es obvia la preferencia capitular por el uso de la polifonía homofónica, severa, con escasos fragmentos imitativos. La intervención polifónica en el oficio de difuntos, tanto con estilo herreriano, en el caso de Juan Muro, o ligeramente adornado, en el caso de Cristóbal de Morales, equilibra un conjunto litúrgico que tiene al canto llano como hilo conductor: el verticalismo polifónico y la armonicidad rítmica de los procesos de cambio se introducen en el ceremonial como elementos de variedad y cohesión.

\section{Óbito de Felipe II}

Los documentos analizados son muy similares entre sí, reflejando algunas diferencias en cuanto a la cantidad y calidad del detalle. En el caso de Felipe II, el secretario del cabildo conquense realizó una descripción muy general, sin apenas referencia a la intervención musical. Los funerales duraron dos días, con un importante gasto de las arcas públicas que alcanzó los 2135 ducados. El oficio religioso comenzó las primeras vísperas, tras el tañido a completas, un día antes de la misa y responso (absoluciones del día de honras). En cuanto a la música, sabemos que únicamente la tercera lectio del primer nocturno fue desarrollada a canto de órgano, el resto de lecciones, salmos y antífonas lo hicieron a canto llano. Cabe agregar dos intervenciones más de cantores de la capilla de música: la primera a cargo de Policarpo Checa, un prometedor infante de coro cuya voz había sido gratificada en fechas anteriores por el cabildo, tal y como leemos en el acta capitular de 21 de enero: Como señalaron veynte ducados de salario a Policarpo, tiple Jnfante del choro, por su boz, ${ }^{16}$ cantor que le fue encomendada la primera lectio; la segunda le correspondió a Juan de Santa Cruz, cantor contralto que murió en 1610, tras 24 años de servicio en la catedral. ${ }^{17} \mathrm{El}$ resto de

${ }^{15}$ El lector interesado en el conocimiento de algunas de las músicas utilizadas en este tipo de celebraciones puede consultar el magnífico trabajo de González Marín, L. A. 2004. Música para exequias en tiempo de Felipe IV. Barcelona, CSIC.

${ }^{16} E$ : $C U c . A C, 86: 6 v .21-\mathrm{I}-1598$. El apunte es relevante ya que, ante la creencia de que los infantillos no podían participar ni el Officium Hebdomadae Sanctae (donde sólo intervenían cantores clérigos) ni tampoco en el Oficcium defunctorum, en el documento conquense se constata la participación directa de un niño cantor, intervención muy cuestionada por la historiografía musical tradicional.

${ }^{17}$ Véase la plantilla de cantores de la Catedral de Cuenca en los años 1611 y 1621 en Anexo 5. 2. 
lecciones hasta completar el oficio fueron adjudicadas según los criterios de rango y antigüedad entre racioneros y canónigos. No disponemos de más datos musicales para establecer con exactitud los puntos de referencia necesarios para un mejor y más oportuno análisis.

La construcción del túmulo quedaba a cargo del Concejo, que organizaba la subasta y pregón de su traza. En esta ocasión se le otorgó la construcción al célebre escultor Alonso Serrano, entonces vecino de Cuenca, por 295 ducados. ${ }^{18}$ Su ubicación y dimensiones quedaron determinadas en las condiciones que el Ayuntamiento decretó para su traza, si bien, no cabía otra posibilidad — dada la importancia del difunto- que situar el catafalco en pleno «corazón» del templo, esto es, el espacio comprendido entre el trascoro y el presbiterio:

Que el dicho túmulo sea de hazer en la santa yglesia de Cuenca en la nabe de los Reyes donde es costumbre de lo hazer para semejantes ocasiones. [...] tiniendo en consideración a que a de tomar todo el largo de la dicha nave y ancho della dexando solo paso y asiento para la justicia e regimiento y inquisición e yglesia y el alto a de ser de la altura que yguale en alto al Cristo que esta en la dicha nave y mas si pareciere convenir. ${ }^{19}$

Aunque el gasto mayoritario de las honras - trigo, cera y vino incluidoscorrespondió al Ayuntamiento conquense, el cabildo también soportó los gastos correspondientes a las necesidades que el aderezo del templo suponía, además de los desembolsos extraordinarios ocasionados por el obligado tañido de campanas: unas campanas que es necesario situar en su contexto temporal y espacial para imaginar el impacto anímico de su efectividad sonora. Estos datos aparecen en el Libro de Cuentas de 1598, donde constan apuntes por 4500 maravedíes, pagados al campanero Juan Giral «por las noches que dobló a la muerte de su Majestad el Rey Felipe II, nuestro señor»; y otros 4500 maravedíes al mismo por el toque de campanas en las honras, «que fueron dos por la tarde y otras por la noche y por la mañana»; además de los 5138 maravedíes pagados al entallador Bartolomé Serrano por los andamios, y cerrar la nave mayor hasta el coro y altar mayor. ${ }^{20}$

\footnotetext{
${ }^{18}$ Véanse los interesantes datos biográficos y comentarios artísticos del artículo de Rokiski Lázaro, M. L. 1980. «Túmulo de Felipe II en Cuenca», en Cuenca, p. 52. El documento original que refiere el túmulo se encuentra en AC, 86: 116v-117. Véase también el texto de Martínez Millán, M. 1988. Historia musical de la Catedral de Cuenca. Cuenca, Publicaciones de la Excma. Diputación Provincial, p. 232.

${ }^{19} \mathrm{AMCu}$. Neg. Pers. Leg. 865, exp. 14, s.f.

${ }^{20}$ Véase $L C$. II: $105 \mathrm{v}$.
} 
Tabla 1

TAÑIDO DE CAMPANAS EN LA CIUDAD DE CUENCA DURANTE LAS HONRAS POR FELIPE II

\begin{tabular}{|l|l|l|}
\hline & \multicolumn{1}{|c|}{ MIÉRCOLES 28-X-1598 } & \multicolumn{1}{c|}{ JUEVES 29-X-1598 } \\
\hline Prima & $\begin{array}{l}\text { Tres dobles largos, de 1 hora de dura- } \\
\text { ción, (de 6: 30 a 7: 30). }\end{array}$ & $\begin{array}{l}\text { «Al alba»: Tres dobles largos, de 1 } \\
\text { hora de duración (de 6: 30 a 7: 30). }\end{array}$ \\
\hline Tercia & $\begin{array}{l}\text { Al tiempo de comenzar el oficio de la } \\
\text { misa mayor: un doble «para avisar a } \\
\text { la ciudad». }\end{array}$ \\
\hline Sexta & $\begin{array}{l}\text { Tres dobles de 1 hora de duración (de } \\
\text { 13 a 14). }\end{array}$ & $\begin{array}{l}\text { En el responso: un doble que dure } \\
\text { «hasta que la ciudad haya vuelto al } \\
\text { Ayuntamiento». }\end{array}$ \\
\hline Completas & $\begin{array}{l}\text { Tras el toque a Completas: un doble } \\
\text { para avisar a la ciudad del inicio del } \\
\text { nocturno. }\end{array}$ & \\
\hline Maitines & $\begin{array}{l}\text { Al final de los tres nocturnos, al } \\
\text { tiempo del Responso: un doble que } \\
\text { dure hasta que regrese la ciudad al } \\
\text { Ayuntamiento. }\end{array}$ & \\
\hline Laudes & $\begin{array}{l}\text { A la noche, «dejados laudes»: tres } \\
\text { dobles por tiempo de 1 hora. }\end{array}$ & $\begin{array}{l}\text { Acabados laudes: tres dobles por } \\
\text { tiempo de 1 hora. }\end{array}$ \\
\hline
\end{tabular}

\section{Óbito de Margarita de Austria}

El contenido del ceremonial litúrgico quedó formalmente vinculado con el anteriormente realizado para las honras de Felipe II, aunque esta vez con mayor magnificencia debido al importante papel otorgado a lo musical y, más concretamente, a la participación de la capilla de música: [...] todo el tiempo que duro el oficio el qual se hiço con mucha Cantoria y solenidad como se requería [...]. ${ }^{21}$ Igual que en la anterior ocasión, el oficio de maitines se realizó durante la tarde anterior a la misa mayor. Los datos obtenidos reflejan un mayor detalle en el orden de los maitines que en el caso de Felipe II, apreciándose una significativa participación de la capilla de música. El Invitatorio inicial fue a canto de órgano, sin que el secretario capitular mencione el nombre del compositor

\footnotetext{
${ }^{21}$ El documento inédito aportado complementa la documentación existente en el Archivo Municipal de Cuenca [AMCu. Sig. 2740. Leg. 826. Exp. 13], en su día analizado en el trabajo de Barrio Moya, J. L. 1983.
} 
escuchado. En esta ocasión fueron interpretadas las lectio 1, 4 y 7 polifónicas por la compostura de Muro, maestro de capilla que fue de la catedral de Cuenca, obra de la que sólo se conservan el Invitatorio y la primera de estas Lectio: no hay duda que este oficio de Juan Muro fue pionero en la Catedral de Cuenca $\mathrm{y}$, dado lo adelantado de las fechas, también en España, junto a las principales composiciones de Juan Vazquez y Morales. ${ }^{22}$ Tanto las lecciones segunda y tercera, realizadas por los cantollanistas Benito de Ordas y Diego Alonso, como las restantes por los canónigos Juan del Pozo Palomino, teniente de deán, y Rodrigo Zapata, tesorero capitular - reservando la octava para el Obispo- indican una combinación peculiar propia de la catedral. Los documentos nos dicen que los salmos y antífonas de los tres nocturnos fueron realizados por dos sochantres y dos salmistas, distribuidos entre los dos coros, alternando la monodía con el coro de capellanes, proporcionando un juego variado de gran efecto.

Otro de los referentes polifónicos en Cuenca fue, después de Juan Muro, el sevillano Cristóbal de Morales. El cabildo determinó la intervención de la capilla de música en el Gradual (Requiem aeternam), Tracto (Absolve Domine), y Secuencia (Dies irae) de la célebre Missa pro defuntis: piezas interpretadas sin solución de continuidad tras la entonación del Kyrie por el sochantre. A dicha intervención se añadió otro motete polifónico, peculiaridad que en la práctica hispana se solía intercalar en la Elevatio. Esta obra quedó reflejada también en los documentos conservados en Cuenca, correpondiendo al Versa est in luctum del conquense Juan de Castro y Mallagaray, discípulo que fue de Felipe Rogier, a la sazón maestro de la Real Capilla de Felipe II. Además fue añadido el muy usado responsorio polifónico Libera me, del que nos dice el padre Rubio:

Aunque pertenece al Officium defunctorum suele ir emparejado con la misa pro defunctis el responsorio Libera me, Domine, por la sencilla razón que, una vez acabada aquella tiene lugar, suele tenerlo, el rito llamado «absolución del túmulo», durante el cual se canta el citado responso..$^{23}$

Entre los cuatro tipos de misas que existen, tal y como consta en Guyes, lib. 4, c. XXIII, q. XXVII, la misa in die obitus seu depositionis es la que correspondería a Reyes, príncipes y nobles, con las oraciones propias de la misa conmemorativa o de aniversario. En esta ocasión el acto tenía que ser solemne y cantado, lo que obligaba a la participación de un mayor número de ministros. Los cargos y dignidades que realizaron esta Misa fueron: Oficiante: el Obispo. Diácono y subdiácono: Arcediano de Cuenca y Sr. Maestrescuela. Caperos: Rodrigo Zapata

${ }^{22}$ CC. P. II. LA. 2. ff. 4-5. Sobre este maestro véase el artículo de Sanz, C. 1968. «El Maestro de Capilla Juan Muro en la Catedral de Cuenca (1583-1591)», en Anuario Musical, 23. Véase también Martínez Millán, M. 1988: 84-93.

${ }^{23}$ Rubio, S. 1983, Historia de música española, 2. Madrid, Alianza Música, pp. 79-88, en p. 80. 
(Prior) y Fernando Laparra. Evangelio: Manuel de Ledesma. Epístola: Alonso Serón. Mitra: Alonso de Rivera. Predicador: Fray Jerónimo Delgado. ${ }^{24}$ Libro: Villa (racionero). Cruz: el semanero de epístola.

Tabla 2

TAÑIDO DE CAMPANAS EN LA CIUDAD DE CUENCA DURANTE LAS HONRAS DE MARGARITA DE AUSTRIA

\begin{tabular}{|c|c|c|}
\hline & 27-XI-1611 & 28-XI-1611 \\
\hline Prima & $\begin{array}{l}\text { Dos dobles de todas las campanas de } \\
6: 30 \text { a } 7: 30 \text {. }\end{array}$ & $\begin{array}{l}\text { «Al alba»: Tres dobles largos, de } 1 \\
\text { hora de duración, de } 6: 30 \text { a } 7: 30 .\end{array}$ \\
\hline Tercia & & Al tiempo de comenzar el oficio. \\
\hline Sexta & Dos dobles a las 13 horas. & \\
\hline Nona & $\begin{array}{l}\text { Un doble a las } 14 \text { horas «adelantando } \\
\text { el relox». }\end{array}$ & $\begin{array}{l}\text { En el responso: un doble largo, hasta } \\
\text { el regreso de las autoridades civiles al } \\
\text { Ayuntamiento». }\end{array}$ \\
\hline Completas & $\begin{array}{l}\text { Tras Completas: un doble largo para } \\
\text { venir la ciudad al nocturno. }\end{array}$ & \\
\hline Maitines & $\begin{array}{l}\text { Al finalal de los nocturnos: un } \\
\text { doble, hasta que regrese la ciudad al } \\
\text { Ayuntamiento. }\end{array}$ & \\
\hline Laudes & $\begin{array}{l}\text { Fin de laudes: dos dobles por tiempo } \\
\text { de } 1 \text { hora. }\end{array}$ & $\begin{array}{l}\text { Acabados laudes: tres dobles por } \\
\text { tiempo de } 1 \text { hora. }\end{array}$ \\
\hline \multicolumn{3}{|c|}{ TOTAL: 9 DOBLES. } \\
\hline
\end{tabular}

El campanero recibió 12 ducados por los 9 dobles que dio en los 9 responsos a canto de órgano, realizados en los 9 días que ordeno el cabildo; más otros 12 ducados por los 18 dobles que dio en tres días, «tres pares cada dia».

\section{Óbito de Felipe III}

El ceremonial conquense contiene algunas similitudes con los celebrados en algunas ciudades españolas - incluso el realizado en la capital del reinocomo también lo era su validez:

${ }^{24}$ Los textos de estas alocuciones dejaban tan honda huella en los oyentes que las imprentas los publicaban íntegros, poco tiempo después de las exequias. Tuvieron una amplia difusión en la época, aunque su interés histórico es mínimo son ejemplares de curioso de contenido. 
TESTAMENTO, y ultima disposición y voluntad de el Rey Don Phelipe III Otorgado en Madrid a 30 de marzo del Año de 1621. [...] que yo tengo Breve de nuestro muy Santo Padre Paulo Quinto, dado en 26 de Março de 1613, en que me concede, que todas las Missas que se dixeren por mi Alma, en qualquier Altar de qualquier Iglesia, sean, y tengan el mismo efecto, como si se dixeran en Altares Privilegiados. ${ }^{25}$

A pesar de un contenido cuya estructura encaja exactamente con el referido en este trabajo, desconocemos las particularidades de la parte musical - que sin duda existió - si bien se desprende que la polifonía no tuvo un lugar destacado:

La primera cosa que hizo su majestad, fue mandar, que en la dicha Iglesia de San Francisco se celebrasse el Aniversario por la buena memoria de este Gran Rey, su padre, el qual se celebro con mucha grandeza, y solemnidad Real; asi la Vigilia, que se cantò el dia de antes, como la Missa, Sermon y Responso, asistiendo a todo su Magestad, y el Serenisimo Infante Don Carlos, su Hermano, con toda la Corte y Nobleza, y con infinitos Religiosos de todas Ordenes. Cantò la Missa de Pontifical el Ilustrisimo Cardenal Sacheti, Nuncio Ordinario de su Santidad, en los Reynos de España [...] En el Coro oficiaron los Cantores y Capilla de Religiosos del propio Convento [...]. Acabada la Missa predicò el Doctor Francisco Sanchez, Predicador de su Magestad; [...] cuyo assumpto fue tratar primeramente, de la memoria de la muerte, y de las miserias de este Valle de Lagrimas, y en segundo lugar tratò de la santidad, penitencias, y limosnas del Catolico Rey Don Felipe Tercero. ${ }^{26}$

Aunque la documentación consultada mantiene un elevado índice de detalle, no referencia el momento exacto en que el cabildo de Cuenca autoriza el uso del canto de órgano en las vísperas de difuntos. En ella el secretario capitular relaciona, con meticulosidad, cada uno de los actos y los fragmentos polifónicos que fueron interpretados por los cantores de la capilla - ajustados en todo a las obligaciones generales impuestas por los decretos y disposiciones romanasconfirmando la utilización particular de una práctica musical de gran austeridad pero muy efectiva en cuanto expresión. ${ }^{27}$

La celebración comienza con la antífona Dirige Domine Deus a la que sigue el salmo verba mea ( $L U: 1782$ ). Como en el óbito de Margarita de Austria, el Invitatorio fue a canto de órgano, todo hace suponer que si en las lecciones 1 (Parce mihi Domine), 4 y 7, el cabildo optó por la sencillez de las composiciones del maestro Juan Muro, también lo haría en el caso del invitatorio - Regem cui omnia - incluido en la composición principal de Muro, únicos números que todavía se conservan. Las antífonas y salmos fueron análogos a los del

${ }^{25}$ Yáñez, J. 1723. Memorias para la historia de don Felipe III, rey de España. Madrid: Nicolás Rodríguez Franco, Impressor de Libros. pp. 347 y 350.

${ }^{26}$ Ibídem, p. 277.

${ }^{27}$ Véase el detalle sobre las músicas aplicadas y su ritmo litúrgico en los Anexos 5.1. y 5.2. 
óbito anterior, ejecutados despacio como en oficio doble, todos a canto llano. El resto de lecciones, y sus correspondientes responsorios, siguieron el orden del Breviario, y fueron entonadas por los racioneros Ordas y Juan Bautista Cañizares (lecciones 2 y 3), los canónigos Fernando Laparra y Manuel de Ledesma (lecciones 5 y 6), y por el Arcediano de Alarcón y el Maestrescuela las dos últimas. En el caso de Cuenca queda probado que se seguía la norma del breviario, realizando los maitines completos, como también los Laudes, en contra de lo que se acostumbraba en otras ciudades de nuestro país:

La etiqueta exigía decir tres nocturnos, sin embargo, la práctica demuestra que a lo largo de todas las exequias del siglo XVII sólo se decía uno. El hecho de no cantar los tres se atribuía en la mayoría de las ocasiones a que era muy de noche cuando se acababa, o en otras a la falta de cera. [...] Algo parecido sucedía con las laudes: aunque estaban establecidas tampoco se decía siempre, y de nuevo el motivo se achacaba a la avanzada hora en la que se acababan los maitines. ${ }^{28}$

Tras la intervención del Maestrescuela (lectio 9) se cantaba el responsorio Libera me Domine viis inferni, a canto llano, dando paso a los laudes, desarrollados de manera convencional. Otro de los momentos de intervención polifónica más esperados - una vez acabados laudes - era la interpretación del responso Libera me Domine de morte aeterna en el momento previo a inciensar el túmulo, mientras que el Preste decía la oración terra inclina, texto utilizado para pedir misericordia..$^{29} \mathrm{En}$ el archivo de la Catedral existe copia del siglo XIX de un fragmento musical cuya ficha catalográfica dice: Morales. Libera me, responso a 4 , sin fecha, ${ }^{30}$ de un estilo equilibrado, muy sobrio y parco en disonancias, donde prevalece el aspecto expresivo frente al alarde técnico. Sin duda concuerda perfectamente con el estilo herreriano de las obras de Muro tratándose, en mi opinión, de la obra que refieren los documentos. En cuanto a la asiduidad de su aplicación nos dice el padre Rubio:

Aunque pertenece al Officium defunctorum suele ir emparejado con la misa pro defunctis el responsorio Libera me, Domine, por la sencilla razón que, una vez acabada

${ }^{28}$ Flores Rodrigo, S. 2005 «La música en las exequias reales de la ciudad de Barbastro en el siglo XVII», en Música y cultura urbana en la edad moderna (ed. A. Bombi, J.-J. Carreras, y M. A. Marín). Valencia: Universidad de Valencia, pp. 299 y 301.

${ }^{29}$ La oración pertenece a Isaias, 27: Expandit eas coram Domino, et oravit in conspectu Rius dicens: Domine Deus Israel, tu es Deus solus omnium regnorum terre, tu fecisti coelum et terra, inclina aurem tuam et audi, salvos nos fac de manu inimicorum nostrorum. Véase al efecto el texto del padre franciscano Diez, F. 1602. Qvince Tratados en los qvales se contienen muchas y muy excelentes consideraciones, para los actos generales que celebran en la Sancta Iglesia de Dios. Salamanca: Imp. Artus Taberniel, p. 349.

${ }^{30} C C$. Secc. XXVII, $n^{\circ} 20$. 
aquella tiene lugar, suele tenerlo, el rito llamado «absolución del túmulo», durante el cual se canta el citado responso. ${ }^{31}$

Nuevamente el cabildo decretó que el Gradual, Tracto y Secuencia fueran los propios de la Missa pro defunctis de Morales. Aunque dicha Misa ha desaparecido del archivo de la Catedral de Cuenca tenemos constancia documental de su existencia encontrándose referenciada en el Inventario del año 1611, donde aparece también el libro de Completas de Juan Muro de cuyo contenido sólo permanece el Invitatorio Regem quen Omnia vivunt, y la primera Lección del primer nocturno, Parce mihi Domine, escritos con una bella polifonía casi homofónica; el resto de composiciones han desaparecido:

Inbentario que se hizo de los libros de canto de organo e motetes y otros que estan en el cajon que para ellos ay en esta sancta iglesia Junto al sagrario, y los tienen para los ofiçios y misas desta sancta yglesia, el qual se hizo siendo obrero della el señor doctor Valençuela canonigo, por Comissión del Cabildo, y se hizo en la forma siguiente: Primeramente vn libro de missas de Morales, que tiene cinco missas de a cuatro, y tres de a cinco. Otro de missas de Morales que tiene tres missas de a cuatro, y tres de a cinco y dos de a seis $[\ldots] .{ }^{32}$

El motete intercalado en la Elevación fue Laboravi, del maestro Juan Muro, obra igualmente desaparecida. En cuanto a la instrucción litúrgica, la misa fue celebrada por el Arcediano de la localidad de Huete, Alonso Télez Girón, realizando la correspondiente prédica el doctor Juan de Pereda y Judice.

\footnotetext{
${ }^{31}$ Entre las obras a destacar se encuentran la Missa pro defunctis, de Cristóbal de Morales, y la homónima de Tomás Luis de Victoria, ya que nos permiten — dada su proximidad temporal y estilística al momento que nos ocupa - definir con exactitud aquellos puntos de referencia necesarios para clarificar la presente aportación. Véase, Rubio, S. 1983, Historia de música española, 2. Madrid, Alianza Música, pp. 79-88, en p. 80.

${ }^{32}$ Fuente Charfolé, J. L. 2007. «Inventarium Librorum Musicae. Nueva aportación documental sobre el Archivo Musical de la Catedral de Cuenca (Siglos XVII-XVIII)», en Anuario Musical, 62, pp. 171-204, en p. 178.
}

Hispania Sacra, LXV

131, enero-junio 2013, 103-138, ISSN: 0018-215-X, doi: 10.3989/hs.2013.004 
Tabla 3

TAÑIDO DE CAMPANAS EN LA CIUDAD DE CUENCA DURANTE LAS HONRAS DE FELIPE III

\begin{tabular}{|c|c|c|c|c|c|}
\hline & 3-IV-1621 & 4-IV-1621 & 5-IV-1621 & 6-IV-1621 & 7-IV-1621 \\
\hline \multicolumn{6}{|l|}{ Prima } \\
\hline Tercia & & & $\begin{array}{l}\text { Acabada } \\
\text { prima: } 3 \\
\text { dobles. } \\
\text { Responso ad } \\
\text { matutinum, } \\
\text { a canto de } \\
\text { órgano. }\end{array}$ & $\begin{array}{l}\text { Acabada } \\
\text { prima: } \\
1 \text { doble. } \\
\text { Responso ad } \\
\text { matutinum. }\end{array}$ & $\begin{array}{l}\text { Acabada } \\
\text { prima: } \\
1 \text { doble. } \\
\text { Responso ad } \\
\text { matutinum. }\end{array}$ \\
\hline \multicolumn{6}{|l|}{ Sexta } \\
\hline Nona & & $\begin{array}{l}\text { Al mediodía } \\
\text { tres dobles. }\end{array}$ & $\begin{array}{l}\text { Al mediodía } \\
\text { tres dobles. }\end{array}$ & & \\
\hline Vísperas & & $\begin{array}{l}\text { Final de } \\
\text { vísperas: un } \\
\text { doble. }\end{array}$ & & & \\
\hline Completas & $\begin{array}{l}\text { Tras comple- } \\
\text { tas se inicia } \\
\text { la procesión } \\
\text { a la nave de } \\
\text { los Reyes de } \\
\text { la Catedral y } \\
\text { se realiza la } \\
\text { oferta cirial: } \\
\text { se ordena un } \\
\text { doble antes } \\
\text { del Responso } \\
\text { y otro doble } \\
\text { al final. }\end{array}$ & $\begin{array}{l}\text { Fin de } \\
\text { completas: } \\
\text { Responso en } \\
\text { la nave de } \\
\text { los Reyes, } \\
\text { a canto de } \\
\text { órgano. }\end{array}$ & $\begin{array}{l}\text { Fin de com- } \\
\text { pletas: un } \\
\text { doble antes } \\
\text { del Responso } \\
\text { en la nave de } \\
\text { los Reyes, } \\
\text { a canto de } \\
\text { órgano. }\end{array}$ & $\begin{array}{l}\text { Fin de com- } \\
\text { pletas: un } \\
\text { doble antes } \\
\text { del Responso } \\
\text { a canto de } \\
\text { órgano. }\end{array}$ & $\begin{array}{l}\text { Fin de com- } \\
\text { pletas: un } \\
\text { doble antes } \\
\text { del Responso } \\
\text { a canto de } \\
\text { órgano. }\end{array}$ \\
\hline \multicolumn{6}{|l|}{ Maitines } \\
\hline Laudes & $\begin{array}{l}\text { Después } \\
\text { de tocar a } \\
\text { oración: tres } \\
\text { dobles. }\end{array}$ & & & & \\
\hline
\end{tabular}

\section{CONCLUSIÓN}

Los datos historiográficos que enmarcan la práctica musical que acompañó a los Austrias en todos los actos cortesanos y exequias realizadas en las principales ciudades de nuestro país, son parciales e incompletos, en gran medida debido 
a la escasez y poca concrección de los detalles musicales contenidos en la documentación conservada: escasez que no quita el indudable interés que supone para el estudio evolutivo de la música polifónica en nuestro país. Bastaría con una consulta a los libros de actas de los principales archivos municipales para obtener información suficiente sobre la intervención musical en las ceremonias obituarias. La dificultad no reside en la cantidad de información sino en la dispersión de ésta, pues sería necesario recorrer las principales ciudades de España para obtener una muestra significativa, de cuyo análisis se beneficiaría enormemente la visión histórico-artística de este fenómeno. Por el análisis documental se conoce que el ambiente era significativamente solemne y luminoso, donde el óbito real superaba la privacidad para convertirse en una ceremonia edificante de interés nacional: en ella tanto el débil como el poderoso podían adivinar la muerte propia recreada en la ajena.

El análisis de los documentos encontrados en la Catedral de Cuenca certifica que la atsmósfera general en que se desarrollaban este tipo de funerales de estado - aun siendo momentos de pesadumbre social - no conllevaba tópicos apocalípticos, ni visiones de oscuridad o terror, como tantas veces ha sido afirmado y confirmado en estudios y recreaciones visuales y auditivas; por el contrario, la terminología contrastada difunde el convencionalismo de la muerte como un trance común a reyes y vasallos, independiente del nivel social del actor. La música y la luminosidad fueron constantes en el desarrollo de estos actos. La luz, mantenida gracias a la enorme cantidad de cera que ardía constantemente tanto en el túmulo como en las diferentes capillas del templo, ${ }^{33}$ y la intervención musical, en perfecta simbiosis expresiva con los textos y tiempos litúrgicos, se unían a los signos, símbolos, colores, cirios, jeroglíficos, calaveras, emblemas y alegorías moralizadoras, formando un todo impactante con el que las gentes piadosas se identificaban ante la certeza de la muerte.

\section{APÉNDICE DOCUMENTAL}

Documento 1. Cuenca, 1598-X-24. Oficio por la muerte de Felipe II

$$
\text { E: CUC.AC, } 86: 112 \mathrm{r}-113 \mathrm{v}
$$

\footnotetext{
${ }^{33}$ Véase la descripción de los elementos que componían la iluminación del túmulo de Felipe III en Documento 4. María Luz Rokiski nos confirma esta apreciación: [...] hay que imaginar que con todas las velas encendidas el efecto debía ser sorprendente. Véase Rokiski Lázaro, M. L. 1980. «Túmulo de Felipe II en Cuenca», en Cuenca, p. 52. Véase también otra constatación documental referida a este punto: [...] se pusieron entre pilar y pilar del trascoro del dicho tumulo diez y seys achas de zera mas abaço del estado de los hijosdalgo pusieron doce achas y en el otro lado mas abaxo los guisados de a caballo pusieron en cada uno seis achas, luego todos los demas cabildos de oficiales pusieron por su horden cada uno seis achas hasta la puerta del perdon que pusieron los herreros otras seis achas de manera que el dicho dia quedo apercibido de ello. [CUm. 2740. Leg. 826. Exp. 13, s.f. ]
} 


\section{Ordenaçion que despues hizieron por comision del Cabildo los señores diputados para lo que toca al tañer y doblar las campanas y hazer el ofiçio.}

En el dicho Cabildo sabado a beynte y quatro de octubre del dicho año de mill y quinientos y nouenta y ocho se juntaron los señores Juan Çapata thesorero, don Françisco Suarez de Cañamares Abad de Sanctiago y el doctor Pedro Gonçalez del Castillo canonigos de la dicha Iglesia como diputados que son por los señores Dean y Cabildo para ordenar y asentar las cosas que fueren a cargo el Cabildo de hazer y proueer para las dichas honrras de su majestad, y attento que esta acordado con la çiudad que se han de començar miercoles a beynte y ocho dias deste mes de octubre dia de los vienauenturados apostoles san Simon y Judas a la tarde despues de las visperas solepnes para lo que toca al doblar de las campanas desta Iglesia y de las parrochias y monasterios que han de seguir a la cathedral y tañer a las oras y hazer el ofiçio ordenaron y proueyeron lo siguiente:

\section{Sobre el doblar y lo que ha de ser a cargo del campanero.}

Y que el miercoles dias de los apostoles san Simon y Judas dada la plegaria de la misa mayor se comiençen a doblar todas las canpanas mayores y menores de la Iglesia y se den tres dobles largos que duren vna hora \f. $112 \mathrm{v} \backslash$ y despues dando la vna ora despues de mediodia hasta las dos oras ha de dar otros tres dobles por la misma orden; Despues de tañido a completas ha de dar otro doble largo para que la çiudad benga, de manera que quando la çiudad venga por la plaça y entrare en la Iglesia este doblando sin çesar; En acabando los tres noturnos y al tiempo del responso se ha de dar otro doble largo que dure hasta que la çiudad aya buelto a sus casas de ayuntamiento; Despues a la noche quando ayan dexado de laudes ha de dar otros tres dobles largos que duren otra ora $\mathrm{Y}$ otro dia, el juebes al Alba, ha de dar otros tres dobles que duren otra ora; Despues a la misa mayor del dia, dada la plegaria de la misa, ha de dar otro doble largo para que benga la çiudad que dure hasta que aya entrado en la Iglesia toda la gente; Despues de la misa de las honrras al tiempo del responso ha de dar otro doble largo que dure hasta que la çiudad aya buelto a las casas del ayuntamiento, y aqui se acaba el doblar de todas las honrras.

\section{If. 113r $\backslash$ Orden para tañer a las oras y el ofiçio como se ha de hazer.}

A las visperas el dia de san Simon y Judas ordenaron que se tañiese a las dos oras como suele, antiçipando el relox media ora, y otro dia juebes se taña a prima de seys y media a siete y media. El Cabildo y la Iglesia no han de entrar en el choro que se ha de hazer en la naue de los reyes hasta tanto que la çiudad aya benido y asentadose en sus asientos; Los caperos al noturno de la tarde han de ser los señores Arçidiano de Huete, que ha de dezir la oración, y el chantre, y Lorenço Gauoto, y don Garçia de Medrano, canonigos; Y otro dia para la 
misa los señores thesorero, y Abad de Sanctiago, y Juan de baraxas, y Evstachio Muñoz, canonigos; Las lectiones que se han de encomendar: La primera lection la diga vn infante de choro, que sera Policarpo [Checa], La segunda lection la diga Juan de Sanctacruz, contralto, La terçera lection la diga toda la capilla de los cantores $\backslash f .113 \mathrm{v} \backslash$ la quarta lection vn medio raçionero mas antiguo, La quinta lection un raçionero entero mas antiguo, las quatro lectiones restantes canonigos y dignidades mas antiguos; ordenaron que se notifique a los heredados de todas las capillas de la Iglesia y a sus capellanes para que el dia de las honrras y la tarde del noturno a visperas tengan las capillas abiertas, limpias y los altares adereçados y con recaudo para los que quisieren dezir misa; Asi mismo mandaron a mi el secretario que notifique a los porteros del Cabildo, Andres Lopez de Cañamares y Joan de Najera, que se encarguen de las llaues de la puerta del choro que ha de ser enfrente de la capilla de la madalena, y guarden el choro de manera que no entre ninguna persona de ninguna condiçion que sea fuera de los benefiçiados de la Iglesia y capellanes, cantores y moços de choro y curas y benefiçiados de la çiudad que han de estar en el choro, so pena de quatro ducados que se les executaran inrremisiblemente aplicados al criar de los niños expositos cobrandolos de sus salarios o provechos, lo qual ordenaron ante my Joanes de Liçaso secretario.

Documento 2. Cuenca, 1611-XI-16. Sobre la muerte de Margarita de Austria.

E: CUc. AC, 99: 80r-82r

\section{Sobre el doblar a cargo del campanero.}

Que el dia que se aya de hazer el noturno, que sera a la tarde de antes del dia en que se ha de dezir la misa de las omrras, dada la plegaria de la misa mayor se comiencen a doblar todas las campanas mayores y menores de la Yglesia, y se den dos dobles largos que duren dos terçios de ora; el mismo dia a la una, despues de medio dia, otros dos dobles por la misma orden; \f. 80v $\backslash$ despues de auer tañido a completas otro doble largo para que la çiudad venga, de manera que dure todo el tiempo que tardare en uenir desde su ayuntamiento y entrare a la yglesia al noturno; en acauando los noturnos, al tiempo del responso, otro doble largo que dure hasta que aya buelto la çiudad al ayuntamiento; a la noche, quando ayan dexado de laudes, dos dobles que duren dos terçios de ora; otro dia de mañana al alba otros dos dobles que duren otros dos terçios de ora; despues, dada la plegaria de la misa del dia, començara otro doble largo que durara hasta que la çiudad aya entrado en la Yglesia a la misa de las homrras; despues desta misa al tiempo del responso a de dar otro doble largo que dure hasta que la çiudad aya buelto a las casas de Ayuntamiento; con lo qual se acaua el doblar.

Que al campanero mande librar el Cabildo doçe ducados por lo suso dicho y los nueue dobles que dio en los nueue responsos que se han dicho a canto de 
organo en los nueue dias que ordeno el Cauildo quando tubo nueua de la muerte acauada la misa conuentual, con lo qual se le auran dado veinte y quatro ducados por que a rresçiuido otros doze por los diez y ocho dobles que dio en tres dias arreo, luego que se supo de la muerte, tres pares cada dia, uno a la mañana, otro a la vna, y otro anocheçido, que fue lo mismo que se le dio en la omrras del rey don Philipe segundo; \f. 81r \que en los dichos dobles sigan a la catedral, haziendo lo mismo despues que ella aya començado, las Parrochias de la çiudad, y se auise a su Abad mayor para que ordene se haga asi.

\section{Orden para tañer a las oras y como se ha de hazer el ofiçio.}

A las visperas, el dia que se hiziere el noturno, se taña a las dos como se suele antiçipando el relox una ora, y otro dia se taña a prima de seis y media; a siete y media el coro de la Yglesia ha de estar en la naue de los reyes a la puerta del perdon, y diuidarase de los legos con las varandas que ay para ellos; no an de entrar en el coro su señoria del señor Obispo, Cabildo e Yglesia, hasta que la çiudad aya venido, y asentadose en sus asientos antes desde la nabe de la capilla de su señoria donde estara el Cabildo para venirle acompañando, vendran en orden por sus coros a ocupar sus asientos; caperos al noturno de la tarde, los señores Arçediano de Cuenca y Mastrescuela, y otro dia para la misa, los señores Thesorero y Prior don Rodrigo Çapata y Fernando la Parra, canonigos.

\section{Leçiones que se han de encomendar y quien las debe dezir.}

El inuitatorio a de ser a canto de organo, la primera liçion dira toda la capilla a canto de organo por el canto que dexo compuesto el maestro de capilla Muro; \f. 81v la segunda el raçionero Ordas; la terçera el raçionero Diego Alonso; la quarta la capilla a canto de organo por el dicho canto de Muro; la quinta el señor canonigo Palomino; la sexta el señor don Rodrigo Çapata, canonigo; la septima la capilla a canto de organo por la dicha conpostura de Muro; la ottaua el señor thesorero; la nouena su señoria del señor Obispo; anse de cantar los salmos de los tres noturnos y laudes despacio, como en el ofiçio doble, aya en cada coro un sochantre y un salmista los quales se leuanten juntos a cantar las antiphonas y con ellos los capellanes; acauados laudes se dira el responso de liberame Domine de morte eterna a canto de organo y el señor Obispo ynçensara el tumulo acompañado de los caperos por la orden que dize el ceremonial; la cruz a de tener a la tarde el semanero de epistola, la misa la ha de dezir el señor Obispo, asistentes los señores Arçediano y Mastrescuela, caperos los dichos señores Prior don Rodrigo Çapata y Fernando la Parra, ebangelio el señor Manuel de Ledesma y epistola el señor don Alonso Seron, Mitra el señor don Alonso de Riuera, todos dignidades y canonigos, Libro el raçionero Villa; Ase de dezir la misa, por la compostura de Morales el canto de organo por el qual a de ser el gradual tracto y sequençia; dirase el motete de uersa es yn luctum, por la compostura de el maestro de capilla Juan de Castro; la cruz a 
de tener el semanero de epistola como a la tarde; \f. 82r $\backslash$ los responsos an de ser çinco, a canto llano el primero subuenite sancti Dey; el segundo que lazarum; el terçero Domine quando generis; el quarto ne recorderis; el quinto y ultimo liberame Domine de morte eterna, este a canto de organo; capellanes que siruan a los quatro prebendados que van a dezir los responsos, Juan Fernandez, Alonso de Ayala, Luis Muñoz y Luis Canton; ynçensar y hechar el agua bendita sea por la orden del ceremonial; que se notifique a todos los prebendados de todas las capillas de la yglesia y a sus capellanes que el dia de las homrras y la tarde del noturno a uisperas tengan las capillas auiertas y bien adereçadas y con racaudo para los que quisieren dezir misa; que se notifique a los porteros del Cabildo Andres Lopez y Juan de Najera que tomen las llabes de la puerta del coro y la guarden de manera que ninguna persona entre en el sino fuere benefiçiado de la Yglesia capellanes cantores y moços de coro y curas y benefiçiados de la çiudad que an de estar en el pena de quatro ducados que se les executaran yremisiblemente para la criança de los niños expositos la puerta a de estar enfrente de la capilla de la madalena.

Documento 3. Cuenca, 1621-IV-2. Acuerdos capitulares ante la gravedad de Felipe III

$$
\text { E: CUC.AC, 109: 34r }
$$

\section{Como se leyo carta de Jorge de Touar secretario de su majestad.}

[mrg. Carta] Por la grabe enfermedad del Rey nuestro señor no van estas cartas como se acostumbra firmadas de su Real mano, a cuya causa tengo orden de auisar a vuestra señoria el trauajoso estado en que se halla \f. $34 \mathrm{v} \backslash$ su salud, anoche lunes como a las doze reçiuio el viatico y dalli a una ora la extrema vncion todo pedido por su magestad, con los actos de tan pio y catholico Rey, y conforme a esta neçesidad ordenara vuestra señoria que en esa santa Iglesia se hagan rogatiuas y oraçiones con tanta deuocion y afecto como pide tan gran aprieto y como conbiene al seruiçio de la Yglesia vnibersal y al particular desta monarchia, guarde Dios a vuestra señoria como deseo, de Madrid 30 de marzo de 1621. Jorge de Touar.

\section{Procesiones y rogativas por la salud del Rey.}

Y asi leida y entendida y visto por los dichos señores Presidente y Cabildo el aprieto con que su Magestad quedaua pues se le auia dado la extrema vnçion se acordo que al punto se comiençen a haçer deprecaçiones por su salud y auiendo lugar desde esta mañana se començase a haçer proçesion con Nuestra Señora del Sagrario fuera o por el ambito de la Yglesia y esta tarde vaxar el cuerpo del glorioso san Julian y se haga con el vna proçesion general alrededor de la Plaza y otro dia siguiente otra con el Santisimo sacramento y para 
dar quenta desta resoluçion y acuerdo que se a tomado a su señoria del señor Obispo lo cometieron a los señores Prior y doctor Aguila \f. 35r $\backslash$ a los quales asi mismo se les dio comision para que todas estas proçesiones las ordenen en la forma que les pareçiere conbenir con sultandolo todo con su Illma y para que en lo que toca a la clereçia y orden acudan a estas procesiones o mande se haga y asi lo acordaron asi mismo acordaron que este dia no aya sermon atento la ocupaçion de la proçesion que se acordo se hiçiese con nuestra Señora del Sagrario por de fuera de las gradas y que acauada se dijere misa solemne de Nuestra Señora con que se leuantaron y paso en presencia de my Chrispiniano de Llarena notario secretario.

\section{Como se hiço la procesion con la imagen de Nuestra Señora.}

E luego acauadas las oras se ordeno e hiço la dicha proçesion lleuando la imagen de Nuestra Señora del Sagrario la qual salio por fuera de las gradas con gran deuocion y asistio a ella su señoria dicho señor Obispo y çiudad a que ocurrieron curas y beneficiados con todas las cruzes de las Parrochias, lleuando la santa Imagen vaxo de un palio cuyas varas lleuaron los regidores desta çiudad y acauada se dijo la misa solemne en el Altar mayor por el señor don Françisco de Alarcon maestrescuela y canonigo y de todo doi fe yo Chrispiniano de Llarena notario secretario.

\section{\f. 35v $\backslash$ Proçesion con el cuerpo del glorioso san Julian.}

Este dia a las dos y media de la tarde se vaxo de su lugar a la capilla mayor el cuerpo del glorioso san Julian cuya arca se abrio con las tres llabes que la del señor Obispo trujo el señor don Pedro Pacheco canonigo y prouisor su sobrino, y el señor don Diego Mazo presidente, y señor don Christobal Tribiño thesorero que tenian las otras dos, y le pusieron en su altar que estaua hecho en el lugar donde se pone la çiudad y adornado de muchas luzes y hecho lo suso dicho se dijeron conpletas y acauadas vino su señoria del señor Obispo aconpañado de señores prebendados y se entro en el sagrario a donde se vistio de Pontifical para haçer el ofiçio y luego se ordeno la proçesion de todos los Cabildos, cruzes de las Parrochias, ordenes de frailes, curas y beneficiados y clereçia, la qual se hiço por alrededor de la Plaza a que concurrio la çiudad con su corregidor y Alcalde mayor, lleuaron el glorioso cuerpo de seis dignidades, y de alli hasta vaxadas las gradas lo lleuaron seis canonigos y desde alli hasta la casa del Valcon raçioneros enteros y de alli hasta \f. 36r \frontero de las casas del ayuntamiento medios raçioneros y de alli hasta tornar a subir la mitad de la Plaça lo lleuaron curas de las parrochias, y de alli hasta tornar junto a las gradas, clerigos del Cauildo de santa Catherina, y de alli hasta el altar donde auia salido, dignidades y canonigos con que se acauo la proçesion la qual fue con grandisima deuocion y quedo el cuerpo en el dicho altar con el mismo adorno, de todo lo qual doi fe yo el dicho Chrispiniano de Llarena notario secretario. 
Documento 4. Cuenca, 1621-IV-3. Anuncio de la muerte de Felipe III

$$
\text { E: CUC. AC, 109: 36v-37v }
$$

\section{Proposiçion açerca de la muerte de su Magestad don Phelipe terçero nues- tro señor.}

Este dia el señor don Diego Maço Presidente propuso como el señor Obispo auia tenido un correo del auiso de la muerte de su Magestad, que murio el miercoles pasado, treinta y uno del mes de marzo deste año, a las nuebe y media de la mañana, por cuya causa se deuia acudir a hazer diferentes prebençiones, que el Cabildo acordase lo que se deuia hazer.

El Cauildo auiendolo conferido se acordo en que todo aquello que se hiço en la muerte del Rey don Phelipe segundo se haga en esta, y mas los responsos que se hiçieron en la muerte de la Reyna Nuestra Señora doña Margarita, y para haçer y ordenarlo todo se cometio a los mismos señores Prior y doctor Aguila, y los dichos señores dijeron como el maestro de ceremonias les auia dicho que al señor Obispo le pareçia que atento se auia resuelto que se subiese al Santisimo del If. 37r $\mathrm{r}$ altar donde esta su tabernaculo esta tarde despues de conpletas se hiçiese por detras del choro que lo dijesen asi. Al Cauildo le parecio que pues no se auia vaxado con musica y concurrir agora la muerte de su magestad no pareçia cosa subirle con ella que su señoria lo considerase, lo qual dijesen a su Illma los dichos señores y los quedaron aguardando, y abiendo ydo boluieron, y dijeron como su señoria deçia que le pareçia muy bien y que al anochezer se puede subir el Santisimo Cuerpo, y que desde esta tarde se pueden començar los responsos y su señoria verna luego a haçerlo por su persona.

El Cauildo lo acordo asi y que los sufragios se hagan en la forma siguiente: que este dia, acabadas completas, se diga un responso a canto de organo y se doblen las canpanas, y vayan todos los prebendados en Proçesion a la nabe de los Reyes donde esta puesto el paño de brocado y alli se digan las oraciones, y [a] los lados del paño se pongan seis blandones con seis hachas blancas, que el canpanero de un doble quando se diga el responso y despues del otros dos, y al anocheçer despues \f. $37 \mathrm{v} \backslash$ de tocar a la oraçion tres dobles. Domingo a medio dia dara otros tres dobles, y otro quando se diga el responso acauadas visperas, y al anochezer otros tres dobles y al responso vno, [lunes] acauada prima y a medio dia tres, y a la tarde acauadas completas otro, y al anocheçer tres. Martes al responso despues de prima uno, y a la tarde otro despues de completas. Miercoles despues de prima al responso, y a la tarde despues de completas otro. Domingo quatro, por la tarde despues de visperas se diga otro responso en la nabe de los Reyes; lunes despues de prima se diga un responso y a la tarde despues de conpletas otro en la misma nabe; martes se digan otros dos de la misma suerte, y miercoles otros dos responsos y todos a canto de organo, y asi lo ordenaron en presençia de my Chrispiniano de Llarena notario secretario. 
Documento 5. Cuenca, 1621-IV-21. Actos por la muerte de Felipe III

$$
\text { E: } C U c . A C, 109: 45 \mathrm{v}-51 \mathrm{v}
$$

\section{Orden para tañer a las horas y como se ha de hazer el ofiçio.}

A las visperas el dia que hubiere el noturno, se taña a las dos oras como se suele, otro dia se taña a prima de seis a siete, el choro de la Yglesia a de estar en la nabe de los Reyes a la parte de la puerta del Perdon y dibidirase con vna varanda de balaustre que ay para ello de los legos, no han de entrar en el coro los señores Dean y Cabildo hasta que la çiudad aya venido y sentados en sus \f. 46r $\backslash$ asientos, y han de yr desde el Cabildo en forma de comunidad Caperos a los noturnos y laudes de la tarde los señores Arçediano de Cuenca y Mastrescuela don Diego del Castillo y Alonso el Pozo, para la misa señores thesorero, mastrescuela, Valençuela, y Ledesma. Ofiçio de la tarde, el ymbitatorio ha de ser a canto de organo, la primera leçion dira toda la capilla a canto de organo por el canto que dexo el maestro Muro, la $2^{\mathrm{a}}$ el raçionero Ordas, la $3^{\mathrm{a}}$ Juan Baptista Cañizares, raçionero, la $4^{\mathrm{a}}$ a cantores por la misma compostura de Muro, la $5^{\text {a }}$ el señor Fernando Laparra, canonigo, la sexta el señor Manuel de Ledesma, canonigo, la setima la capilla por la misma compostura de Muro, la ottaua el señor Arçediano de Alarcon, la nouena el señor Mastrescuela, y en acauando la nona leçion se ha de dezir el responso de liberame Domine vijs Inferni a canto llano, los psalmos de los noturno y laudes se han de dezir despacio como en el ofiçio doble, \f. $46 \mathrm{v} \backslash$ a de auer en cada coro un sochantre y vn psalmista los quales se lebanten juntos a cantar las Antiphonas y con ellos los capellanes, acauadas laudes se dira el responso de liberame Domine de morte eterna, a canto de organo. El señor Arçediano de Huete toma capa y estola y ençiensa el tumulo acompañado de los capellanes, y diçe la oraçion terra inclina domine, la cruz a de tener a la tarde el semanero de epistola, la misa a de dezir el señor Arçediano de Huete, ase de dezir la misa por la compostura de Morales el canto de organo por el qual a de ser el gradual tracto y sequençia, dirase el motete de Juan Muro que tiene por titulo laboraui que acordo el Cabildo se dixese en el que tubieron a veinte y dos de mayo, los responsos an de ser çinco, el primero subenite sancti dey, el $2^{\circ}$ qui laçarum, el $3^{\circ}$ domine quando veneris, el $4^{\circ}$ non recorderis, el $5^{\circ}$ y ultimo liberame domine de morte eterna, el qual a de dezir la capilla a canto de organo, y el preste la oración; capellanes que siruan a los quatro prebendados que van a dezir los responsos: Herbias, Hernando, Alonso \f. 47r \Valera, y Miguel Garçia; ynçensar y hechar el Agua vendita: sea por la orden del ceremonial.

Que se les notifique a todos los heredados de todas las capillas de la Yglesia y a sus capellanes que el dia de las homrras, y la tarde del noturno a visperas, tengan los capellanes las capillas aviertas y bien aderezadas, y con recado para los que quisieren dezir misa; que se les notifique a los porteros del Cabildo, Andres 
Lopez y Françisco de Cañamares, que tomen las llabes de la puerta del coro y le guarden de manera que ninguna persona entre en el si no fuere beneficiado de la Yglesia, capellanes, cantores y moços de coro, y curas y beneficiados de la çiudad, que han de estar en el pena de quatro ducados que se les executaran yremisiblemente para la criança de los niños expositos; la puerta a destar frontero de la capilla de la Magdalena, que Pedro de Valera, capellan de san Illefonso, en nombre del Cabildo y de su parte conbide a los prelados de los combentos de la çiudad, y que no traygan mas que un compañero consigo por la estrecheça que abra en el coro, en donde el maestro de zeremonias los acomodara como deben estar sin que otra persona se entremeta en ello ni combidar en su lugar a nadie, que el sacristan del sagrario adereçe el altar donde \f. $47 \mathrm{v} \backslash$ se ha de dezir la misa con su dosel de terçiopelo negro y a los lados paños del mismo terciopelo, de manera que quede cubierta toda la frontera que se ha de ver por los claros del tumulo, que ansimismo adorne el coro para la Yglesia que a de estar arrimado a la puerta del perdon ocupando dos claros de dos arcos de la nabe, diuidiendose de la çiudad con la rexa de balaustres que esta dicho colgando las puertas del perdon y la pared de paños de terçiopelo negro, que todas las ordenes de monasterios de frayles que el dia de las homrras suelen venir a la Yglesia mayor y cada una haze su ofiçio con noturno y misa en capillas que se les señalan si vinieren mandados por el señor Obispo o embiados por la çiudad, que de una manera o otra es combiniente que vengan y suelen venir; les señalaron para hazer sus ofiçios las capillas siguientes: a los clerigos de santa Catherina la capilla del marques de Cañete; a los frayles dominicos la capilla de las diez; a los Françiscos la de los Caualleros; a los de la compañia de Jesus la de Damian Suarez; a los agustinos la de Sanctiago; a los trinitarios la de Constantino; a los Françiscos descalços la de san Honorato; a los merçenarios la de don Juan de Barreda; en las quales hagan sus ofiçios de noturno, misa y responso, que no podran venir al tumulo por la \f. 48r $\backslash$ ocupaçion y embaraço que alli abra, y traygan consigo sus ornamentos solamente, que la çiudad prouehe de la çera vino y ostias que fueren menester para los dichos ofiçios y misa, como le debe y suele hazer en semejantes occasiones, y dandoles para ellos a los sacristanes de la Yglesia y capillas buen recado y con mucha puntualidad para que ellos lo tengan en darlo, todo lo qual les pareçio ser neçesario ordenar y prebenir para la puntualidad y buen conçierto que en todo debe aber, remitiendolo al Cabildo para que lo vea y añada y quite lo que le pareçiere, y hecho lo mande executar; ansi mismo dixeron los señores Presidente y Cabildo mandaron repartir de manuales en las homrras que se hizieron por el rey don Philipe nuestro señor segundo deste nombre, el año de mil y quinientos y nouenta y ocho, y en las que se hizieron por la Reyna doña Margarita de Austria, Nuestra Señora, el año de mil y seisçientos y onçe, ocho reales por raçion para los prebendados desta Yglesia que asistieron a ellos, quatro a los noturnos, y quatro a la misa, que les pareçe que ahora deuen mandar hazer lo mismo para que acudan todos y demas 
de su obligaçion les obligue a ello, con lo qual disoluieron la junta y todo se acordo y paso ante my Chrispiniano de Llarena notario secretario.

\section{If. $48 \mathrm{v} \backslash$ Sobre el pagar al campanero.}

Trataron luego de pagar al campanero lo pasado, de los tres dias que doblo y lo que ahora a de doblar, y considerado que ha tenido y tiene mucha costa de peones, y para darles de comer y jornales que la çiudad no acostumbra dar mas de seys ducados ni en estas homrras diçe dara mas, el Cabildo mande que se le cumplan hasta treinta ducados, y que los veinte y quatro se le den y libren en la fabrica, los otros doze por los dobles que dio en los tres dias, y los otros doze por lo que ahora a de doblar en las homrras, y ansi lo mandaron asentar con lo qual se leuantaron de dicho Cabildo, y paso ante my Chrispiniano de Llarena notario secretario.

\section{Como se hizieron las homrras.}

Hizieronse las homrras en los mismos dias y como estaua ordenado. Vino la çiudad sola con su corregidor y Alcalde mayor, que salieron de las casas de su ayuntamiento en dos yleras, como se acostumbra; sentados el corregidor y el alcalde mayor en la punta del vanco que hazian cabeçera, porque no ubo sillas ninlf. 49rlgunas, y en esta forma en dos yleras de vancos consecutiuos estauan todos los regidores y ministros que con ellos vinieron, todos con lobas y capirotes de vayeta de Sivilla, cubiertas las cabeças, dixo la misa de las homrras don Alonso Tellez Giron, Arçediano de Huete, como mas antigua dignidad, diacono y subdiacono, dos raçioneros enteros que fueron [en blanco], predico el señor doctor don Juan de Pereda y Judice, canonigo de la Magistral desta sancta Yglesia, el señor Obispo no estubo en el lugar.

\section{Relaçion del tumulo que se hizo y su traza.}

Hizo la çiudad un tumulo en la nabe de los reyes, devaxo de la grada del Cristo que esta en lo trascoro, de sesenta y ocho pies de alto, dos pies menos de toda la altura de la nabe, y veinte y quatro pies de ancho en quadra; levantose el primer suelo de nueue pies de alto en que se dividieron, en esta altura, nueue gradas por la parte de delante de todo el ancho de la nabe, y sobre este suelo se hizo el sitial de bulto con un parapeto de valaustre alrededor deste andeto que çircundaba todo el, en que se pusieron treinta y dos candeleros de plata con belas amarillas, y alrededor del tumulo ubo veinte y quatro acheros $\backslash f .49 \mathrm{v} \backslash$ con otras tantas achas amarillas, y el bulto era leuantado nuebe pies ençima destas gradas, en figura tumbada, y ençima del se hecho el paño de Broçado de la Yglesia y una almoada de tela de brocado amarilla en la cabeçera del, y una corona ençima, que fue la mas rica de la ymagen de Nuestra Señora del Sagrario, y un estoque dorada la guarniçion y la cruz del ygnum cruçis, con dos candeleros dorados con dos belas de çera amarilla ençendidas, a la parte de avajo y en el dicho suelo 
se levanto el primero cuerpo sobre doçe colunas doricas, tres en cada esquina, la altura dellas era de veinte y dos pies y un pedestral que lleuaua deuajo de seis pies de alto con un corredor de balaustres ençima de la cornisa que daua buelta alrededor por un lado y otro, la qual cornisa con friso y alquitrabe tubo quatro pies de alto, y entre las columnas tres achas en cada coluna la suya que fueron doze, y en los dos lados, ençima de cada balaustre, una acha en su achero, y ençima desta cornisa su cornisamento al peso de las colunas resaltando en ellos, y ençima deste cornisamento otro corredor de balaustres al plomo de los pedestrales, y ençima de cada balaustre vn çirio grande, y en las esquinas otros tres pedestrales en cada una de las colunas que venian al peso dellos sobre [los] que se lebantaban doçe \f. 50r \ piramides en cada coluna la suya, coronadas en las quatro partes de belas ençendidas y con una bola ençima de dos pies de diametro, y su achero, ençima de cada vola, con su acha; y luego en este propio suelo se leuanto otro cuerpo quadrado de onçe pies de alto dexando un andito alrededor de tres pies; y luego sobre este segundo cuerpo se levanto otro, cuadrado, con su cornisamento y alrededor su corredor de balaustres con vna piramide en cada esquina y ençima della su achero con su acha, y en cada balaustre su vela, dexando de andito otros tres pies a donde se armo vn pedestral de seis pies de alto y ençima una piramide grande con çien belas alrededor, y sobre esta piramide una bola de dos pies y medio de diametro donde iba una cruz por remate que llegaua a frisar con la clabe de la nabe, y en la delantera, en la portada resaltada en medio del pontispiçio, llebaua un escudo de siete pies de alto que venia a ygualar con el corredor del primer suelo con las armas reales, y en el segundo cuerpo en el recuadro de delante llebaua una figura de vna muerte, y este tumulo todo fue pintado de piedra berroquina y de negro y amarillo por algunas partes, y sembrado de escudos de armas por todo el y en las partes que le hera de mucho ornato; \f. 50v tenia en el primer cornisamento y salian quatro banderas grandes devaxo de las piramides donde se estendian azia fuera y frisauan en la cantoria, y en el corredorçillo del piramide del remate salian otras quatro de las claraboyas, que cayan a los lados de las piramides de delante, con sus escudos de armas dorados de una parte y de otra; todo este tumulo hazia vna figura muy agradable y con mucho conçierto y proporçion hecho, y con mucha çera, que fueron en cantidad de mas de seisçientas belas amarillas de a media libra y setenta y seis achas, que satisfaçia mucho el gusto de todos los que le miraban por que la traça fue muy buena y excogida de muchas que se hizieron, los pilares todos de la nabe, desde las del tumulo hasta las de la puerta del perdon, estaban colgados de bayetas de medio avaxo y sembradas de escudos de armas, y en todos los claros de los arcos de una parte y otra en cada uno dellos, desde el trascoro hasta la puerta del perdon, auia seis achas que las pusieron todos los Cabildos por sus antigüedades; y los estados de los hijosdalgo, y quitados de caballo pusieron a doze achas; y desde los pilares del Cruçifixo hasta las espaldas del coro de vna parte y otra puso todas las \f. 51r $\backslash$ achas la çiudad, 
porque la inquisiçion ni por parte del señor Obispo no pusieron ninguna. El altar donde se dixo la misa se lebanto, y la mesa ençima de la cornisa donde antes estaua la reja del trascoro formose un sitio de doçe pies en ancho y veinte de largo, y ençima deste sitio se formo la mesa del altar, con un dosel de terçiopelo negro con que se leuanto ençima de los remates del trascoro, y a los lados deste dosel se pusieron otros paños de terçiopelo negro con que se cubrio toda la frontera que se miraba por el claro del tumulo, y deste sitio se vajaua por tres gradas a otra mesa espaçiosa que venia a juntar con el suelo del andito que çircundaba el bulto con su paso de balaustres y todos estos sitios ornados dellos. El coro para la Yglesia se puso arrimado a la puerta del perdon, ocupando el claro de dos arcos de la nabe, diuidiendose del sitio de [la] çiudad con un antepecho de balaustres que cruçaua toda la nabe y las puertas del perdon y la pared, todo estrangulado y cubierto de paños de terçiopelo negro, la çiudad se puso desde esta baranda hasta las gradas del tumulo, estando çerrados todos los claros de los arcos de toda la nabe en altura de una repia. Y esto fue todo el aparato \f. $51 \mathrm{v} \backslash$ y hornato que tubo el tumulo y todo el sitio de la nabe donde se hizieron las homrras de su magestad. Vbo dos puertas en dos claros de la nabe que la primera fue para el coro de la Yglesia, frontero de la capilla de la Madalena cuia guarda fue el portero del Cabildo, y la otra en la otra parte frontero de la capilla de don Geronimo de Anaya de la advocaçion de san Bartholome, cuia guarda fueron los alguaçiles por auer de entrar por ella la çiudad; todas las ordenes de los monasterios de frayles, el dia de las homrras, vinieron a la Yglesia mayor, y cada vna hizo su ofiçio con noturno y misa en capillas que les fueron señaladas, acauando alli el ofiçio con su responso que no vino ninguno dellos ni entraron en el lugar del tumulo, saluo los prelados con vn compañero en el coro, con la Yglesia, al tiempo de la misa y sermon y hasta acabar todo el ofiçio, que se acauo dada la vna. Vbo infinita gente de la çiudad que no se podia andar por la Yglesia y todos los corredores de la nabe, de una parte y de otra, ocupados de mucha gente. A todo lo qual me alle presente yo, el dicho Chrispiniano de Llerena, notario secretario.

Documento 6. Cuenca. Gasto de las honrras del Rey don Phelipe $3^{\circ}$ deste nombre, nuestro señor.

$$
\text { E: CUC. LC, 13: 456r }
$$

Treze mill cuatrocientos y cuarenta y ocho mrs que se hiçieron de gastos en las honrras del Rey don Phelipe nuestro señor, tercero deste nombre, que murio en 30 de marzo de 621, en esta manera:

- A Juan del Villar por los jornales suyos y de los oficiales que pusieron la escalera para vajar el cuerpo de señor san julian en 2 de abril

\section{i $U \operatorname{cccc}^{\circ} \mathrm{xc}$ vi}

Hispania Sacra, LXV 131, enero-junio 2013, 103-138, ISSN: 0018-215-X, doi: 10.3989/hs.2013.004 
- Al dicho 50 reales por haçer el altar para deçir las i U dcc - missas de las honrras

- 52 mrs de meter las mesas para el dicho altar $\quad$ - U - 1 ii

- A Alonso de Apontes campanero por decreto del x U cc - cabildo de 19 de junio de 621, por el trauajo de doblar las campanas desta yglesia quando vino la nueba de la muerte de su majestad y en sus honrras, mostrolo con este despacho

De lo qual mostro cartas de pago

xiii $\mathrm{U} \mathrm{cccc}^{\circ} \mathrm{cl}$ viii ${ }^{\circ}$

\section{Terno negro}

Treinta y quatro mill seisçientos y noventa y siete mrs que monto y pago de toda costa [por] vn terno negro de raso prensado que se hiço para el offiçio de difuntos, supuesto el rasso que lo dejo comprado el señor don Pedro Çapata en esta manera:

- Del precio de 41 varas de tafetan en que se aforro ix $\mathrm{U} \mathrm{dc} 1$ viii $^{\circ}$ dicho terno, a 7 reales la vara

- A Juan Martinez sastre de la hechura de las dos capas, casulla, dalmatitas, stolas y manipulos, corchetes y otros recados como pago por quenta que dio

- Del preçio de 23 onças de oro que entraron en la guar- ix U d lx niçion, esto sin lo que se tenia la fabrica

- Del preçio de una libra de seda joyante que se compro ii $\mathrm{U}$ dcc 1 vi para dicha guarniçion

- A Fabian de Montoya, cordonero de la hechura de la vii $\mathrm{U} \mathrm{decc^{0 }} \operatorname{lxxx} \mathrm{v}$ guarniçion del franjon, de oro y seda y molinillos con que se guarnecio

De todas las quales cosas mostro cartas con cartas de $\quad x_{x x i v}{ }^{0} U$ dexc vii pago

$\backslash 456 \mathrm{v} \backslash$

- Del preçio de 10 varas de tafetan blanco para aforrar ii $U \operatorname{dccc}^{\circ} \mathrm{xc}$ dicha ropa y la vieja

- A Juan Martinez, sastre, de seda y echura de las dichas i $U \mathrm{~d} l \mathrm{xxx}^{\mathrm{O}} \mathrm{i}$ dos ropas y hechar el forro a la vieja 
De todo lo que mostro cartas de pago

xxix $U \mathrm{cc}$ xl -

\section{Ropa para los moços de choro}

Veinte y nuebe mill y cuarenta y ocho mrs que costaron de toda costa doze ropas de paño de media grana para los mozos de choro en esta manera:

- Del preçio de 42 varas de dicho paño, a 28 reales la xcv U dcc - iiii ${ }^{\circ}$ vara monta

- De tundir dicho paño, a 24 mrs la vara

i $U$ - - viii ${ }^{\circ}$

- Del porte de traer desde Madrid a esta çiudad el dicho $\quad U$ cc xc vi paño, que peso 3 arrobas

- A Juan Martinez sastre por la hechura de las dichas ii $U$ - xl ropas, a 5 reales cada vna

De todo lo qual mostro cartas de pago

xxix $U-x l$ viii

AneXos

Ceremoniale Episcoporum

Lib. 2, cap. x, pp. 84-86.

$\mathrm{Si}$ aderit in Ecclesia lectus mortuorum, seu castrum doloris, et si Missa celebrata sit pro anima alicuius Summi Pontificis, vel Sanctae Ecclesiae Cardinalis, seu Metropolitani, aut Episcopi propii, seu Imperatoris, Regis vel Ducis magni, aut Dominici loci, conveniens est ut fiant absolutiones apud castrum doloris, tam ab ipso Episcopo celebrante, quam ab aliis quatuor Episcopis, vel Prelatis, si adsunt ; et in defectum Episcoporum, a quauor primis dignitatibus, vel Canonicis, ordine infrascripto; videlicet finita Missa et sermone [...] \p. 85\ Iunior Praelatus sedebir in scabello in angulo castri dolores ad pedem dexterum, alius post eum in angulo ad humerum finistrum, tertius in angulo ad pedem sinistrum, quartus, qui erit senior, in angulo ad humerum dextrum. Celebrans vero sedebit in faldistorio in capite loci in medio, ita ut crucem directe respiciat. Omnibus sic ordinatis, surget celebrans, detecto capite, omnibus similiter surgentibus, et incipet in tono lectionis absolute orationem [Non intre in iudicio \&c] qua finite, omnes sedebunt coopertis capitibus, et cantores incipient Responsorium [Subvenite Sancti Dei \&c] tunc duo acoliti cum thuribulo et navicula et aqua benedicta, et aspersorio accedent ad angulum dexterum capitis, ubi est dignior Praelatus, et sed ad eius dexteram collocabunt. Incepto versiculo [Requiem aeternam \&c] Acolitus 
dabit naviculam Diacono, et ipse accedet cum thuribulo ante dictum digniorem Praelatum, quae ministrante Diacono naviculam, imponet thus in thuribulum. Cum per thorum dicetur primum [Kyrie eleison] surgent omnes, detectis capitibus; et predictus dignior Praelatus voce intelligibili dicet [Pater noster] quod secrete complebit: et interim accepto aspersorio cum aqua benedicta de manu Diaconi, asperget lectum circumcirca ambulas, incipiens a sua parte dextera, tercio aspergens quamlibet lecti partem; Diacono a sinistris comitante, et simbrias pluvialis sublevante: et dum transibit ante eos Prelatos, illos salutabit [...] Cum redierit post thurificationem ad locum sum, ante scabellum stans dicet Versiculos [Et ne nos \&c] et alios Versiculos, et Orationem [Deus, cui omnia vivunt \&c] prout in Pontificali. Quae finita, omnes sedent cum mitra, et cantores incipient Responsorium [Qui Lazarum \&c] dum dicent Versiculum [Requiem aeternam] [...] dicto ultimo [Kyrie eleison] a choro, surget, omnibus simileter surgentibus dicet [Pater noster] asperget, et thurificabit lectum ut supra, et demun dicet Versiculos, et Orationem [Fac quae sumus \&c]. Qua finita, omnes similiter sedebunt, et cantores cantabunt Responsorium [Domine, quando veniet \&c] et tertius dignior Praelatus sedens ad sinistrum humerum servabit omnia, quae superius primus, et secundus superaverunt, et demum dicit Orationem [Inclina, Domine, aurem tuam \&c] Qua similiter finita, quartus, et iunior Praeslatus sedens in angulo ad dexterum pedem faciet similiter, et in fine dicet orationem [Absolve, quae sumus, ut in resurrectione \&c] Demum cantato a choro, Responsorio [Libera me, Domine, de morte aeterna $\& c]$ celebrans ipse imposito thure in thuribulo, ut supra, dicto [Pater noster] asperget, et thurificabit lectum, prout de primo, et aliis dictum est, et in fine dictis Versiculis, dicet orationem [Absolve quae sumus \&c] et responso per chorum [Amen] ipse Episcopus dicet [Requiem aeterna, \&c] et demum duo cantores dicent \p. 86\ [Requiescat in pace] [...] Quatuor, seu quimque istas absolutiones non semper in omnibus exequiis fieri convenit, sed tantum in primis exequiis, quae solent fieri post obitum, ut sunt exequiem novemdiales, quae in Romana curia fiunt pro anima Pontificis defuncti.

Plantilla de cantores y ministriles de los años 1611 y 1621.

E: $C U C . L C, 13: 335 \mathrm{r}$ y $450 \mathrm{v}$, respectivamente.

(1611)

Juan de Castro y Mallagaray

14 Infantes de coro

Agustín de Castro

Pedro López

Francisco de Caruda
OFICIO

Maestro de Capilla

Tiples

Cantor (tiple)

Cantor (tiple)

Cantor (tiple)
(1621)

Juan de Castro y Mallagaray

12 Infantes de coro

Agustín de Castro

Pedro López

Juan de Loarte 


\author{
Policarpo Checa \\ Juan de Santa Cruz \\ Lope García \\ Geronimo Malo
}

Sebastián Gutierrez

-

Juan Calvo

Pedro Marchado

Domingo de Montenegro

Alejo de Rosales

Antonio de Nogueras

Francisco Márquez

Andrés López de Cañamares

Josephe Ysasi

Pedro de Madrid

Pedro García

Pedro de Alcubilla

Alonso de Córdoba

Bartolomé de Selma

Juan García Sotos Albos

Francisco de Tolosa

$$
\text { Juan Aparicio }
$$

Juan de Rioja

-
-
-
llón

Juan de Castellón

Pedro Rodriguez

$$
\begin{aligned}
& \text { Cantor (tiple) } \\
& \text { Cantor (tiple) } \\
& \text { Cantor (tiple) }
\end{aligned}
$$

Cantor (contralto)

Cantor (contralto)

Cantor (contralto)

Cantor (contralto)

Cantor (tenor)

Cantor (tenor)

Cantor (tenor)

Cantor (bajo)

Cantor (bajo)

Organista

Organista ayudante

Organista

Corneta

Chirimía

Sacabuche

Sacabuche

Sacabuche

Sacabuche

Sacabuche

Bajón

Salmista

Salmista

Salmista

Salmista

Salmista

$-$
Sochantre

Sochantre

Violín

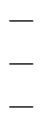

Bartolomé Ramirez

Julián Guesca

Francisco Vinier

Lope García

Juan Calvo

Cristóbal de Medrano

Pedro Sánchez

Juan Gerónimo

-

Francisco Márquez

Andrés López de Cañamares

$-$

-

Juan Azero

Pedro García

Julián García

-

$-$

$-$

Juan Aparicio

Cristóbal López

Domingo García

Juan Cañas

Francisco Peláez

Hernando de Alcocer

-

Josephe de Santos

Orden general de la liturgia defunctorum

E: CUc. $(A C, 1598-1621)$

[E] Recitado / [G] Canto llano / [P] Polifonía / [R] Responsorio / [S] Salmo / [A] Antífona [LU] Liber Usualis 


\begin{tabular}{|c|c|c|c|}
\hline \multicolumn{4}{|c|}{ MAITINES } \\
\hline$\stackrel{\frac{0}{0}}{g}$ & \multicolumn{2}{|c|}{ Invitatorio: Regem cui Omnia. [P] } & Venite exultemus [G] \\
\hline \multirow{3}{*}{ 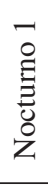 } & $\begin{array}{l}\text { Lectio } 1[\mathrm{P}] \\
\text { Parce mihi }\end{array}$ & \multirow{3}{*}{ R. 1-3 [G] } & \multirow{8}{*}{$\begin{array}{l}\text { Salmos y antífonas: } \\
\text { los correspondientes a cada nocturno. } \\
\text { El cabildo indica que deben ser } \\
\text { despacio, como en oficio doble. }\end{array}$} \\
\hline & Lectio $2[\mathrm{G}]$ & & \\
\hline & Lectio $3[\mathrm{G}]$ & & \\
\hline \multirow{3}{*}{$\begin{array}{l}\text { r } \\
\stackrel{2}{0} \\
\dot{0}\end{array}$} & Lectio $4[\mathrm{P}]$ & \multirow{3}{*}{ R. 4-6 [G] } & \\
\hline & Lectio $5[\mathrm{G}]$ & & \\
\hline & Lectio $6[\mathrm{G}]$ & & \\
\hline \multirow{3}{*}{$\begin{array}{l}m \\
\dot{0} \\
\dot{z}\end{array}$} & Lectio $7[\mathrm{P}]$ & \multirow{2}{*}{ R. 7-8 [G] } & \\
\hline & Lectio $8[\mathrm{G}]$ & & \\
\hline & Lectio $9[\mathrm{G}]$ & $\begin{array}{c}\text { R. 9: Libera me Domini } \\
\text { viis inferni }[\mathrm{G}]\end{array}$ & $\begin{array}{l}1621 \text { (M. García) } \\
1611 \text { (J. Fernández) }\end{array}$ \\
\hline
\end{tabular}

\begin{tabular}{|c|c|}
\hline \multicolumn{2}{|l|}{ LAUDES } \\
\hline v. Deus in adjutorium & $\begin{array}{l}\text { S. 69-70. Doxologia menor. } \\
\text { Laus tibi }[\mathrm{G}]\end{array}$ \\
\hline $\begin{array}{c}5 \text { Salmos con sus antífonas. } \\
\text { Benedictus Dominus Deus Israel }[\mathrm{G}] \\
\text { Versículos finales y Benedicamus Domino. } \\
\text { Responso: Libera me Domine de morte aeterna }[\mathrm{P}]\end{array}$ & \\
\hline
\end{tabular}

Rito de absolución del túmulo. Preste: Terra inclina Domine [E]

\begin{tabular}{|c|c|c|}
\hline \multicolumn{3}{|c|}{ MISSA PRO DEFUNCTIS } \\
\hline Introductio & Requiem aeternam & S. Te decet $[\mathrm{G}]$ \\
\hline Kyrie & {$[\mathrm{G}]$} & \\
\hline \multicolumn{3}{|c|}{ Lecturas } \\
\hline Gradual & Requiem aeternam $[\mathrm{P}]$ & v. In memoria $[\mathrm{G}]$ \\
\hline Tracto & Absolve $[\mathrm{P}]$ & v. Et gratia tua $[\mathrm{G}]$ \\
\hline Secuencia & Dies irae $[\mathrm{P}]$ & \\
\hline \multicolumn{3}{|c|}{ Evangelio } \\
\hline Offertorium & A. Domine Iesu $[\mathrm{G}]$ & \\
\hline Sanctus \& Agnus & [G] & \\
\hline Comunnio & A. Lux aeterna $[\mathrm{G}]$ & \\
\hline Post-comunnio & Requiescat in pace $[\mathrm{G}]$ & \\
\hline
\end{tabular}

Hispania Sacra, LXV

131, enero-junio 2013, 103-138, ISSN: 0018-215-X, doi: 10.3989/hs.2013.004 


\begin{tabular}{|c|c|c|c|}
\hline \multicolumn{4}{|c|}{ QUINQUE ABSOLUCIONES [ $L U: 1823]$} \\
\hline \multirow{5}{*}{ 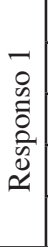 } & \multicolumn{3}{|c|}{ Subvenite [LU: 1765] [G] } \\
\hline & \multicolumn{3}{|c|}{ Kyrie eleison [entonado] + Pater noster } \\
\hline & \multicolumn{3}{|c|}{ A. In Paradisum [G] } \\
\hline & \multicolumn{3}{|c|}{ [Oración] } \\
\hline & \multicolumn{3}{|c|}{ Cántico de Zacarías [G] } \\
\hline $\begin{array}{l}\sim \\
\dot{2} \\
\stackrel{0}{\sim}\end{array}$ & $\begin{array}{l}1621 \text { (F. Laparra) } \\
1611 \text { (A. de Ayala) }\end{array}$ & $\begin{array}{l}\text { Qui Lazarum } \\
\text { [LU: } 1786]\end{array}$ & Hasta v. Requiem aeternam [G] \\
\hline \multirow{3}{*}{$\begin{array}{r}m \\
\dot{0} \\
\stackrel{0}{2}\end{array}$} & $\begin{array}{l}1621 \text { (A. Téllez) } \\
1611 \text { (Luis Muñoz) }\end{array}$ & $\begin{array}{c}\text { Domine quando } \\
\text { veneris } \\
{[L U: 1787]}\end{array}$ & v. Requiem aeternam $[\mathrm{G}]$ \\
\hline & \multicolumn{3}{|c|}{ Kyrie eleison $[\mathrm{E}]+$ Pater noster } \\
\hline & \multicolumn{3}{|c|}{ Oración: Inclina Domine aurem tuam [LU: 1824] } \\
\hline $\begin{array}{l}+ \\
\dot{2} \\
\stackrel{0}{2}\end{array}$ & $\begin{array}{l}1621 \text { (P. de Valera) } \\
1611 \text { (Luis Cantón) }\end{array}$ & $\begin{array}{l}\text { Ne recorderis } \\
{[L U: 1792]}\end{array}$ & v. Requiem aeternam $[\mathrm{G}]$ \\
\hline \multirow{6}{*}{ 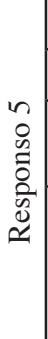 } & \multicolumn{3}{|c|}{ Libera me Domine de morte aeterna $[\mathrm{P}]+$ versículos [LU: 1767] } \\
\hline & \multicolumn{3}{|c|}{ Oración : Absolve, quaesumus Domine [E] } \\
\hline & \multicolumn{3}{|c|}{$\begin{array}{l}\mathrm{V}: \text { Requiem aeternam dona eis Domine }[\mathrm{E}] \\
\mathrm{R} \text { : Et lux perpetua luceat eis }[\mathrm{E}]\end{array}$} \\
\hline & \multicolumn{3}{|c|}{ Chantre } \\
\hline & & $\because \cdots$ & $\Leftrightarrow \circ$ \\
\hline & & qui-es-cal in & R.A. $\operatorname{men}-$ \\
\hline
\end{tabular}

\section{BIBLIOGRAFÍA}

Aldazabal, J. 1993. La celebración de las exequias. Barcelona: Centre de Pastoral Litúrgica.

Allo Manero, A. y Esteban Lorente, J. F. 2004. «El estudio de las exequias reales de la monarquía hispana: siglos XVI, XVII, XVIII», en Artigrama, 19, pp. 39-94.

Barrio Moya, J. L. 1983. «Las honras fúnebres de la Reina Margarita de Austria en la Catedral de Cuenca», en Cuenca, 21 y 22, pp. 53-63.

Campos y Fernández de Sevilla, J. 2001. «Exequias en honor de Felipe III celebradas en Lima en 1621», en Hispania Sacra, 53, pp. 327-344.

Ceremoniale Episcoporum iussu Clementis VIII, Pontificis Maximi novissime reformatum. Omnibus ecclesiis, praecipue autem Metropolitanis, Cathedralibus \& 
Collegiatis per utili, ac necessarium. Venetiis Ex Typographia Nicolai Misserini, Anno Iubilar MDC, Mense Septembris.

Collado, Francisco J. 1869. Descripción del túmulo y relación de las exequias que hizo la ciudad de Sevilla en la muerte del rey don Felipe II. Sevilla: Ed. Francisco de Borja Palomo (Bibliófilos Andaluces).

Correa, B. 1977. «Los túmulos de Felipe III y Margarita de Austria en la Catedral de Sevilla», en Archivo Hispalense, 185, pp. 149-176.

Cuesta Hernández, L. J. 2008. «Mexico insigne honras celebro a su rey: algunas precisiones sobre el ceremonial fúnebre de la dinastía de los Austrias en la Nueva España», en Via Spiritus, 15, pp. 111-136.

Flores Rodrigo, S. 2005 «La música en las exequias reales de la ciudad de Barbastro en el siglo XVII», en Música y cultura urbana en la edad moderna (A. Bombi, J.-J. Carreras, M. A. Marín, eds.) Valencia: Universidad de Valencia, pp. 295-305.

González Marín, L. A. 2004. Música para exequias en tiempo de Felipe IV. Barcelona, CSIC.

Hoppin, R. H. 1991. La música medieval. (Trad.: Pilar Ramos). Madrid: Akal Música.

Lázaro,E. 1963. «Año de 1598: Muere Felipe II», en Boletín del Excmo.Ayuntamiento de Cuenca, año IX, $\mathrm{n}^{\circ} 33$.

López Calo, J. 1988. Historia de la música española, 3. siglo XVII. Madrid: Alianza Música.

Martínez Gil, F. 2000. Muerte y sociedad en la España de los Austrias. Cuenca: Ediciones de la UCLM.

Martínez Millán, M. 1988. Historia musical de la Catedral de Cuenca. Cuenca, Publicaciones de la Excma. Diputación Provincial.

Rigual, J. (trad.) 1805. Oficio de difuntos, orden de los entierros, los siete salmos penitenciales, con la Letanía de los Santos, y las Oraciones de la Iglesia contra las tempestades. Madrid: Imprenta Real.

Rokiski Lázaro, M. L. 1980. «Túmulo de Felipe II en Cuenca», en Cuenca, 14 y 15, pp. 49-54.

Rubio, S. 1983. Historia de la música española, 2. Madrid: Alianza Música.

Torre García, E. 2000. «Los Austrias y el poder: la imagen en el siglo XVII», en Historia y Comunicación Social, número 5, pp. 13-29.

Yáñez, J. 1723. Memorias para la historia de don Felipe III, rey de España. Madrid: Nicolás Rodríguez Franco, Impressor de Libros. 